\title{
The KCNQ1 (Kv7.1) COOH Terminus, a Multitiered Scaffold for Subunit Assembly and Protein Interaction ${ }^{*[5}$
}

Received for publication, April 6, 2007, and in revised September 10, 2007 Published, JBC Papers in Press, December 29, 2007, DOI 10.1074/jbc.M707541200

\author{
Reuven Wiener ${ }^{\ddagger 1}$, Yoni Haitin ${ }^{\S}$, Liora Shamgar ${ }^{\S}$, M. Carmen Fernández-Alonso", Ariadna Martos ${ }^{\ddagger}$, \\ Orna Chomsky-Hecht ${ }^{\ddagger}$, Germán Rivas", Bernard Attali ${ }^{\S}$, and Joel A. Hirsch ${ }^{\ddagger 2}$ \\ From the ${ }^{\ddagger}$ Department of Biochemistry, The Daniella Rich Institute for Structural Biology, Faculty of Life Sciences, \\ and the ${ }^{\S}$ Department of Physiology and Pharmacology, Faculty of Medicine, Tel Aviv University, \\ Ramat Aviv 69978, Israel and "CIB-Consejo Superior de Investigaciones Científicas, E-28040 Madrid, Spain
}

The Kv7 subfamily of voltage-dependent potassium channels, distinct from other subfamilies by dint of its large intracellular $\mathrm{COOH}$ terminus, acts to regulate excitability in cardiac and neuronal tissues. KCNQ1 (Kv7.1), the founding subfamily member, encodes a channel subunit directly implicated in genetic disorders, such as the long QT syndrome, a cardiac pathology responsible for arrhythmias. We have used a recombinant protein preparation of the $\mathrm{COOH}$ terminus to probe the structure and function of this domain and its individual modules. The $\mathrm{COOH}-$ terminal proximal half associates with one calmodulin constitutively bound to each subunit where calmodulin is critical for proper folding of the whole intracellular domain. The distal half directs tetramerization, employing tandem coiled-coils. The first coiled-coilcomplexis dimericand undergoes concentrationdependent self-association to form a dimer of dimers. The outer coiled-coil is parallel tetrameric, the details of which have been elucidated based on $2.0 \AA$ crystallographic data. Both coiledcoils act in a coordinate fashion to mediate the formation and stabilization of the tetrameric distal half. Functional studies, including characterization of structure-based and long QT mutants, prove the requirement for both modules and point to complex roles for these modules, including folding, assembly, trafficking, and regulation.

The KCNQ channels represent a subfamily of voltage-gated $\mathrm{K}^{+}(\mathrm{Kv})^{3}$ channels, whose members (Kv7.1-5) are expressed in a wide variety of tissues. These channels play a major role in brain and cardiac excitability through the modulation of the

* This work is supported in part by Israel Science Foundation Grant 672/05 and Wolfson Family funds (to B. A.) and by Israel Science Foundation Grant $1201 / 04$ (to J. A. H.). The costs of publication of this article were defrayed in part by the payment of page charges. This article must therefore be hereby marked "advertisement" in accordance with 18 U.S.C. Section 1734 solely to indicate this fact.

The atomic coordinates and structure factors (code 3BJ4) have been deposited in the Protein Data Bank, Research Collaboratory for Structural Bioinformatics, Rutgers University, New Brunswick, NJ (http://www.rcsb.org/).

5 The on-line version of this article (available at http://www.jbc.org) contains supplemental Table 1 and Figs. 1 and 2.

${ }^{1}$ Supported in part by a matching Tel Aviv University Rector doctoral fellowship.

${ }^{2}$ To whom correspondence should be addressed: Dept. of Biochemistry, Faculty of Life Sciences, Tel Aviv University, Ramat Aviv 69978, Israel. Tel.: 9723-640-6211; Fax: 972-3-640-7931; E-mail: jhirsch@post.tau.ac.il.

${ }^{3}$ The abbreviations used are: $\mathrm{Kv}$, voltage-gated $\mathrm{K}^{+}$channel; $\mathrm{CaM}$, calmodulin; LQT, long QT; PBS, phosphate-buffered saline; ICP, inductively coupled plasma; WT, wild type; NHS, $\mathrm{N}$-hydroxysulfosuccinimide. cardiac potential waveform, the regulation of action potential generation and propagation, the tuning of neuronal firing patterns, and the modulation of neurotransmitter release $(1,2)$. Mutations in human $K C N Q$ genes lead to major cardiovascular and neurological disorders, such as the cardiac long QT syndrome or neonatal epilepsy (3).

Like all Kv channels, the KCNQ $\alpha$ subunits share a common core structure of six transmembrane segments with a voltagesensing domain (S1-S4) and a pore domain (S5-S6) (see Fig. $1 A$ ), likely to approximate the mammalian Kv1.2 channel $\alpha$ structure described by MacKinnon and co-workers (4). Often, KCNQ $\alpha$ is in complex with the integral membrane auxiliary subunit, known as KCNE1, IsK, or MinK. This protein alters channel properties, such as single channel conductance and activation kinetics while increasing channel density in the plasma membrane (5).

Several structural features of the Kv7 $\alpha$ family members distinguish them from the larger Kv channel superfamily. In particular, their primary sequence encodes a large (300-500 residues), intracellular $\mathrm{COOH}$ terminus (Fig. 1A). Sequence analysis predicts four helical regions (dubbed A-D) present in all family members (6). Helices C and D are thought to form coiled-coil assemblies. Yeast two-hybrid screens for proteins interacting with the $\mathrm{COOH}$ terminus revealed $\mathrm{CaM}$, the ubiquitous $\mathrm{Ca}^{2+}$ sensor protein, as a binding partner $(6-8)$. Moreover, CaM constitutively associates with the channel (6-10). Helices A and B encode the binding site for CaM, and CaM association is required for proper channel assembly and function $(6,7,9)$. LQT mutations that disrupt or significantly weaken the CaM interaction result in little or no complex and little channel expression in live cells $(8,11)$. Thus, CaM acts as an additional auxiliary subunit of the KCNQ channel complex. Additionally, $\mathrm{Ca}^{2+}-\mathrm{CaM}$ is a $\mathrm{Ca}^{2+}$ sensor for $\mathrm{KCNQ} 1$ function, transducing $\mathrm{Ca}^{2+}$ signals to stimulate $I_{\mathrm{KS}}$ channels and producing a $\mathrm{Ca}^{2+}$-dependent left shift in the voltage dependence of channel activation. This $\mathrm{Ca}^{2+}$-sensitive $I_{\mathrm{KS}}$-current stimulation could increase the cardiac repolarization reserve, preventing the risk of ventricular arrhythmias.

Biochemical and functional studies have identified Kv7 $\mathrm{COOH}$-terminal regions important for channel tetramerization and trafficking (12-16) based on deletion, truncation, and mutagenesis. Little work has directly examined on a protein level the postulated structural modules and their functional correlates. What precisely is the tertiary and quaternary organization of the $\mathrm{COOH}$ terminus, and what does it do that dis- 


\section{Structural and Functional Studies of the KCNQ1 COOH Terminus}

tinguishes it from the other Kv channel subfamilies? Using a recombinant bacterial co-expression system (8), we have dissected the KCNQ1 COOH terminus protein complex. Our findings suggest that the $\mathrm{KCNQ} 1 \mathrm{COOH}$ terminus may be divided into two parts, where the membrane proximal half is important for functional expression, folding, and gating of the channel but not oligomerization, whereas the membrane distal half directs folding, oligomerization, partner specificity, and trafficking to the plasma membrane. This $\mathrm{COOH}$ terminus is a multifunctional platform, employing relatively simple structural modules to assemble a channel with high specificity in an apparent hierarchical manner.

\section{EXPERIMENTAL PROCEDURES}

\section{General Subcloning and Mutagenesis}

For bacterial expression vectors, PCR was used to engineer BamHI and NotI restriction sites onto the specific human KCNQ1 gene fragments. PCR product was ligated into doubly digested (BamHI and NotI) modified pETDuet vector. This pETDuet vector contains a His ${ }_{8}$ tag sequence and TEV protease recognition sequence upstream to multiple cloning site I with CaM inserted into multiple cloning site II. Positive clones were identified by restriction analysis and subsequently sequenced in all DNA constructs described below. In addition, all site-directed mutagenesis was performed by the QuikChange (Stratagene) method. Altered sequences were confirmed by DNA sequencing.

Subcloning of $\Delta$ Helix $C$-The KCNQ1 sequence in a pcDNA3 vector was used as a template for QuikChange, where primers were designed to delete helix C (residues 548-565). This modified vector then served as the template for PCR of an insert for the pETDuet vector.

Subcloning of $\Delta$ Loop-Construction was in two steps. First, PCR was used to engineer BamHI and EcoRI restriction sites onto a KCNQ1 gene fragment (residues 352-386). PCR product was ligated into a doubly digested (BamHI and EcoRI), modified pETDuet vector. Then PCR was used to engineer EcoRI and NotI restriction sites onto an additional gene fragment (residues 504-622). This PCR product was ligated into doubly digested (EcoRI and NotI) modified pETDuet vector already contained the fragment encoding residues 352-386.

Subcloning of COOH Terminus-GCN4-LI Chimera-Subcloning was in two steps. First, PCR was used to engineer BamHI and EcoRI restriction sites into the KCNQ1 gene fragment (residues 352-594). PCR product was ligated into doubly digested (BamHI and EcoRI) modified pETDuet vector. Then the GCN4-LI sequence (encoding IEDKLEEILSKLYHIENELARIKKLLG) was amplified by primers containing EcoRI and NotI sites in the $5^{\prime}$ - and the $3^{\prime}$-flanking regions, respectively. GCN4-LI PCR product was ligated into doubly digested (EcoRI and NotI) modified pETDuet vector that already contained DNA encoding residues 352-594. Subsequently, the EcoRI restriction site was deleted by mutagenesis.

\section{Expression and Purification of the Various KCNQ1 COOH Terminus-CaM Complexes}

Transformed Escherichia coli BL-21 Tuner (Novagen), containing the "RIL" Codon Plus ${ }^{\mathrm{TM}}$ plasmid (Stratagene) cells were grown at $37^{\circ} \mathrm{C}$ in LB medium, containing $100 \mu \mathrm{g} / \mathrm{ml}$ ampicillin, and $34 \mu \mathrm{g} / \mathrm{ml}$ chloramphenicol. Upon reaching an $A_{600}$ of 0.3 , the temperature was lowered to $16^{\circ} \mathrm{C}$, and growth continued until the culture reached an $A_{600}$ of 0.6. Protein expression was induced with $135 \mu \mathrm{M}$ isopropyl 1-thio- $\beta$-D-galactopyranoside. Cells were harvested after $14 \mathrm{~h}$ by centrifugation, frozen, and suspended in $120 \mathrm{ml}$ of lysis buffer, buffer L (300 mM NaCl, 50 mm sodium phosphate, $\mathrm{pH} 8,1 \mathrm{~mm}$ phenylmethylsulfonyl fluoride). After lysis by a microfluidizer (Microfluidics), cell debris was removed by centrifugation at $20,000 \times g$. The soluble fraction was loaded onto a pre-equilibrated metal chelate $\mathrm{Ni}^{2+}$ CAM (Sigma) column (buffer A: $300 \mathrm{~mm} \mathrm{NaCl}, 50 \mathrm{~mm}$ sodium phosphate, $\mathrm{pH} 8$ ) at a flow rate of $1.0 \mathrm{ml} / \mathrm{min}$. The column was washed with buffer A, containing $10 \mathrm{~mm}$ imidazole, until a stable base line was achieved. After elution with buffer A, supplemented with $125 \mathrm{~mm}$ imidazole, the protein eluate was then subjected to TEV protease in a ratio of 1:150. The proteolysis continued for $12 \mathrm{~h}$. Subsequently, the sample was diluted 4-fold with $10 \%$ glycerol and loaded onto a pre-equilibrated SP-Sepharose (Amersham Biosciences) column (buffer S: 50 $\mathrm{mm} \mathrm{NaCl}, 20 \mathrm{~mm}$ Tris, $\mathrm{pH}$ 7.5). The column was then washed with buffer $S$, and fractions were eluted with a shallow linear gradient of buffer $\mathrm{S}$, containing $50-600 \mathrm{~mm} \mathrm{NaCl}$. Fractions were pooled and applied to a pre-equilibrated Superose 6 gel filtration column (Amersham Biosciences) with buffer F (150 $\mathrm{mm} \mathrm{NaCl}, 20 \mathrm{~mm}$ Tris, pH 7.5, 1 mM dithiothreitol). The elution peak was concentrated to $3 \mathrm{mg} \mathrm{ml}^{-1}$ using spin concentrators (Vivascience), divided into aliquots, and flash-frozen in liquid $\mathrm{N}_{2}$. For purification of $\Delta$ helix D, $\Delta$ helices C-D, and $\Delta$ loopCaM complexes, a Superdex-200 gel filtration column was employed instead of the Superose- 6 gel filtration column.

\section{Subcloning, Expression, and Purification of GST-Helix C and GST-Helices C-D}

Both KCNQ1 gene fragments (residues 535-572 or 535-622, respectively) were amplified by PCR with primers containing BamHI and NotI sites in the $5^{\prime}$ - and 3 '-flanking regions, respectively. PCR product was ligated into doubly digested (BamHI and NotI) pGEX 4T-1 vector (Amersham Biosciences). Expression was as above. Cells were suspended in phosphate-buffered saline (PBS) (pH 7.4) with $1 \mathrm{~mm}$ phenylmethylsulfonyl fluoride. After lysis, cell debris was removed by centrifugation. The soluble fraction was loaded onto a pre-equilibrated glutathioneSepharose column (buffer A: PBS, pH 7.4), at a flow rate of 1.0 $\mathrm{ml} / \mathrm{min}$. The column was washed with buffer A and eluted with buffer B (100 mM Tris pH 8, $100 \mathrm{~mm} \mathrm{NaCl,} 20 \mathrm{~mm}$ glutathione), and the protein was applied to a pre-equilibrated Superdex 200 gel filtration column with buffer F. The elution peak was concentrated and stored as above.

\section{Expression and Purification of Selenomethionine Protein}

The selenomethionine $\Delta$ loop-CaM complex was prepared by inhibition of the methionine pathway. Inoculum was grown from a single transformed colony in 10\% LB medium. The cells were pelleted, and media supernatant was removed, prior to the addition to 2 liters of New Minimal Medium, containing Kao and Michayluk vitamin solution (Sigma), $100 \mu \mathrm{g} / \mathrm{ml}$ ampicillin, and $34 \mu \mathrm{g} / \mathrm{ml}$ chloramphenicol. Upon reaching an $A_{600}$ of 0.3 , 
the temperature was lowered to $16^{\circ} \mathrm{C}$. Lysine, phenylalanine, and threonine (100 $\mathrm{mg} /$ liter), isoleucine, leucine, and valine (50 $\mathrm{mg} / \mathrm{liter}$ ), and DL-selenomethionine (50 mg/liter) were added $45 \mathrm{~min}$ before induction, when the culture reached an $A_{600}$ of 0.6. Protein expression was induced with $135 \mu \mathrm{M}$ isopropyl 1 -thio- $\beta$-D-galactopyranoside over a 16 -h period. Purification of the selenomethionine protein was similar to that of the native protein, except that $5 \mathrm{~mm} \beta$-mercaptoethanol was added to all solutions to prevent oxidation of the selenomethionine derivative protein.

\section{Peptide Purification}

The helix D synthetic peptide (residues 585-621, acetylated and amidated at the $\mathrm{NH}_{2}$ and $\mathrm{COOH}$ termini, respectively) was purified by reverse-phase high pressure liquid chromatography using a C18 column (Vydac) with a shallow acetonitrile gradient of 35-60\% (both solvents were supplemented with $0.05 \%$ trifluoroacetic acid).

\section{Analytical Ultracentrifugation}

Sedimentation velocity analysis of the different protein samples were carried out at 40,000 or $50,000 \mathrm{rpm}$ and $5{ }^{\circ} \mathrm{C}$ (except $\Delta$ helices $\mathrm{C}$-D and point mutants that were centrifuged at $10^{\circ} \mathrm{C}$ ) in an XL-A analytical ultracentrifuge (Beckman-Coulter Inc.) with a UV-visible optics detection system, using an An60Ti rotor and 12-mm double sector centerpieces. All of the proteins were equilibrated in $20 \mathrm{~mm}$ Tris- $\mathrm{HCl}, 150 \mathrm{~mm} \mathrm{NaCl}, 0.1 \mathrm{~mm}$ dithiothreitol, pH 7.5, buffer except for CT-GCN4LI, which was in PBS. The sedimentation velocity runs were done at different protein concentrations ranging from 0.1 to $1.5 \mathrm{mg} / \mathrm{ml}$. Sedimentation profiles were registered every $5 \mathrm{~min}$ at the appropriate wavelength (ranging from 230 to $280 \mathrm{~nm}$ ). The sedimentation coefficient distributions were calculated by leastsquares boundary modeling of sedimentation velocity data using the $\mathrm{c}(s)$ method (17) as implemented in the SEDFIT program. The corresponding standard $s$-values $\left(s_{20, w}\right)$ were obtained from the experimental $s$-values upon correction for density, viscosity, and protein concentration (18), using the SEDNTERP program (19).

Sedimentation equilibrium experiments were carried out at multiple speeds (9000, 13,000, 22,000, 32,000, 40,000, and $43,000 \mathrm{rpm})$ and wavelengths (230, 238, 250, and $280 \mathrm{~nm})$ with short columns $(80 \mu \mathrm{l})$ using the same instrumentation and conditions as described above. In order to determine the stoichiometry of the two KCNQ-CaM complexes, the sedimentation equilibrium data of these macromolecular mixtures were analyzed assuming the linear approximation of the buoyant molecular weights $(20,21), b M_{w, i j}=i b M_{w, A}+j b M_{w, B}$, where $i j$ refers to the complex $A_{i} B_{j}$, and $b M_{w, A}$ and $b M_{w, B}$ are the buoyant molecular weights of pure $A$ and pure $B$, respectively. In this case, the weight-average buoyant molecular masses $\left(b M_{w}\right)$ were determined from the sedimentation equilibrium data by fitting a single species model to the experimental data using either a MATLAB program based on the conservation of signal algorithm (22) (kindly provided by Dr. Allen Minton, National Institutes of Health) or the HeteroAnalysis program (20); both analytical methods gave essentially the same results. The molecular masses of the single solute components (helix D pep- tide and $\mathrm{CaM}$ ) were determined from the corresponding experimental buoyant values using 0.734 and $0.732 \mathrm{~cm} / \mathrm{g}$ as the partial specific volumes of peptide and CaM, respectively, calculated from the amino acid composition using the SEDNTERP program.

\section{Spectroscopy}

All measurements were done with an Aviv CD spectrometer model 202. Spectra were measured over the range of 260-180 $\mathrm{nm}$ at a scan rate of $1 \mathrm{~nm} / \mathrm{s}$. A cell with $0.1-\mathrm{mm}$ path length was used. Each spectrum is an average of five scans. The raw data were corrected by subtracting the contribution of the buffer to the signal. Then data were smoothed and converted to molar ellipticity units. Protein concentration was determined using the predicted extinction coefficient at $280 \mathrm{~nm}$. For melting experiments, CD was measured at $222 \mathrm{~nm}$ with a $1-\mathrm{mm}$ path length cell. Temperature equilibrium time was $2 \mathrm{~min}$, and integration time was $30 \mathrm{~s}$. The CD data were scaled from 0 to 1 with respect to the initial native form and the fully unfolded form using the equation,

$$
C D_{\text {scaled }}=\frac{C D_{\text {obs }}-C D_{\text {initial }}}{C D_{\text {final }}-C D_{\text {initial }}}
$$

\section{Analytical Gel Filtration Chromatography}

Proteins were injected onto a Superose 6 10/300 GL or Superdex 200 10/300 GL or Superdex 75 10/300 GL (Amersham Biosciences) column. Proteins were eluted with buffer $\mathrm{F}$ at a flow rate of $0.5,0.7$, or $0.8 \mathrm{ml} / \mathrm{min}$ for Superose 6 , Superdex 200, or Superdex 75 columns, respectively.

\section{Crystallization}

Crystals were grown in 12-16\% polyethylene glycol 8000, 0.1 $\mathrm{M}$ Tris, $\mathrm{pH} 7-8$, at $19^{\circ} \mathrm{C}$ by sitting drop vapor diffusion. Equal volumes $(1 \mu \mathrm{l})$ of frozen stock protein $(15 \mathrm{mg} / \mathrm{ml})$ were mixed with reservoir solution. Native crystals appeared after 2 weeks. Heavy atom soaks were prepared by adding $1 \mathrm{~mm} \mathrm{~K}_{2} \mathrm{ReCl}_{6}$ directly to drops containing crystals for $24 \mathrm{~h}$. Four selenomethionine protein crystals appeared after several months. Crystals were cryoprotected by sequential dilution with reservoir solution, including $24 \%$ glycerol, and then loop mounted and flash frozen in liquid $\mathrm{N}_{2}$.

\section{Structure Determination}

Diffraction data were obtained under standard cryogenic conditions and processed with HKL (23). We executed a single wavelength anomalous diffraction experiment on the selenomethionine crystals, using the anomalous selenium peak. Heavy atom site location and experimental phases calculation was performed with CNS (24) and $\operatorname{SHARP}(25,26)$, respectively. Multiple isomorphous replacement with anomalous scattering from the selenium and rhenium derivative data sets against the native data set were used for experimental phase calculation. Subsequent density modification with SOLOMON (26) gave electron density maps of excellent quality. An initial model was built with ARP/wARP (27) and subsequently refined with Refmac5 (28) with rounds of model building. 


\section{Structural and Functional Studies of the KCNQ1 $\mathrm{COOH}$ Terminus}

\section{Electrophysiology}

Recordings were performed using the whole cell configuration of the patch clamp technique. Signals were amplified using an Axopatch 200B patch clamp amplifier (Axon Instruments), sampled at $2 \mathrm{kHz}$ and filtered at $800 \mathrm{~Hz}$ via a 4-pole Bessel low pass filter. Data were acquired using pClamp 8.2 software in conjunction with a DigiData $1322 \mathrm{~A}$ interface. The patch pipettes were pulled from borosilicate glass (Warner Instrument Corp.) with a resistance of 4-7 megaohms. The intracellular pipette solution contained $130 \mathrm{~mm} \mathrm{KCl,} 1 \mathrm{~mm} \mathrm{MgCl}_{2}, 5$ $\mathrm{mm} \mathrm{K}_{2} \mathrm{ATP}, 5$ mm EGTA, 10 mm HEPES, adjusted with $\mathrm{KOH}$ to pH 7.4 (290 mOsm). The external solution contained $140 \mathrm{~mm}$ $\mathrm{NaCl}, 4 \mathrm{~mm} \mathrm{KCl}, 1.8 \mathrm{~mm} \mathrm{CaCl}_{2}, 1.2 \mathrm{~mm} \mathrm{MgCl}_{2}, 11 \mathrm{~mm}$ glucose, 5.5 mm HEPES, adjusted with $\mathrm{NaOH}$ to $\mathrm{pH} 7.4$ (310 mOsm). Series resistances (8-15 megaohms) were compensated (75$90 \%)$ and periodically monitored.

\section{Immunocytochemistry}

COS7 cells were grown on 13-mm diameter coated glass coverslips in 24-well plates. Cells were rinsed for $5 \mathrm{~min}$ in PBS and subsequently fixed for $20 \mathrm{~min}$ in $4 \%$ paraformaldehyde in PBS. Following extensive washes in PBS, the cells were permeabilized by incubation with $10 \%$ normal goat serum in PBS containing $0.2 \%$ Triton X-100 for 20 min. Cells were then washed twice for 10 min each in PBS containing 1\% normal goat serum. Cells were incubated at $4{ }^{\circ} \mathrm{C}$ overnight with a rabbit antiKCNQ1 (Alomone Laboratories) channel or mouse anti-FLAG (M2; Sigma) antibodies. After a $3 \times 5$-min wash in PBS, cells were incubated for $1 \mathrm{~h}$ at room temperature with secondary antibodies, CY2-conjugated anti-rabbit IgG (1:200; Jackson Immunoresearch) and RRX-conjugated anti-mouse IgG (1:1000; Jackson Immunoresearch), respectively. Cells were viewed, and digital images were taken using a Zeiss 510 META confocal microscope using the 488-nm argon or 543-nm HeNe excitation laser lines.

\section{Cell Surface Biotinylation Assays}

Biotinylation of surface proteins was carried out by incubating cells with $1 \mathrm{mg} / \mathrm{ml}$ EZ-Link Sulfo-NHS-SS-Biotin (Pierce) in PBS containing $1 \mathrm{~mm}$ phenylmethylsulfonyl fluoride and 5 mM EDTA (solution A) for $30 \mathrm{~min}$ at room temperature. The reaction was terminated by incubating cells for $5 \mathrm{~min}$ in solution A containing $20 \mathrm{~mm}$ glycine, followed by three washes in solution A. Cells were lysed in buffer P (50 mм Tris- $\mathrm{HCl}, \mathrm{pH}$ 7.5, 20 mм HEPES, pH 7.5, 150 mм NaCl, 5 mм EDTA, 1.5 mm $\mathrm{MgCl}_{2}, 10 \%$ glycerol (w/v), $1 \%$ Triton X-100 (v/v)), containing 1 $\mathrm{mM}$ phenylmethylsulfonyl fluoride and $10 \mu \mathrm{l} / \mathrm{ml}$ protease inhibitor mixture (Sigma), for $1 \mathrm{~h}$ at $4{ }^{\circ} \mathrm{C}$ under rotation. Cell lysate was cleared by centrifugation, and biotinylated proteins were precipitated by incubation with streptavidin-agarose beads (Pierce) overnight at $4{ }^{\circ} \mathrm{C}$. The beads were washed six times with buffer P. Proteins were eluted by incubation with sample buffer at room temperature and then resolved by SDSPAGE and Western blotted.

\section{Inductively Coupled Plasma (ICP) Spectrometry}

Peptide samples were suspended at room temperature in a mixture of metal chloride salts containing Tris (10 mM), $\mathrm{pH} 7.5$,
$100 \mathrm{~mm} \mathrm{NaCl}$, and a $20 \mu \mathrm{M}$ concentration of the indicated metals for $2 \mathrm{~h}$ at $0.35 \mathrm{mg} / \mathrm{ml}$. Subsequently, peptide was dialyzed for $16 \mathrm{~h}$ against the same buffer without metals. Samples were prepared for analysis by incubation in a hot water bath at $80^{\circ} \mathrm{C}$ for $2 \mathrm{~h}$ with the following addition. One-ml volumes of concentrated nitric acid were added to 1-2-ml sample batches in polypropylene $50-\mathrm{ml}$ tubes. Liquid residues were taken up in deionized water and made up to a 10-ml volume with the same solvent. Metal concentration in the acid extract was determined by ICP atomic emission spectrometry. An ICP atomic emission spectrometer with cross-flow nebulizer was used (Spectroflame Modula E from Spectro, Kleve, Germany).

\section{RESULTS}

Oligomeric State of the KCNQ1 COOH Terminus-CaM Complex-Work by Pitt and co-workers (11) suggested previously that a soluble KCNQ1 COOH terminus-CaM complex is tetrameric using chemical cross-linking, consistent with the universal tetrameric structure of $\mathrm{Kv}$ channels. Using a similar molecular complex, comprising soluble $\mathrm{COOH}$ terminus and constitutively bound CaM (Fig. 1, $B$ and $C$ ), we probed its oligomerization state (i.e. its molecular weight) by sedimentation equilibrium analysis. The results indicate that the complex is best modeled as a tetramer with four subunits of KCNQ1 $\mathrm{COOH}$ terminus and four bound molecules of CaM (Fig. 1D). Data analysis, assuming a single sedimenting solute species, yields a buoyant molecular weight of 54,000 \pm 3000 (solid line). This value is very close to that calculated from the addition of the buoyant molecular weights of four molecules of the $\mathrm{COOH}$ terminus $(4 \times 8400)$ and four of CaM $(4 \times 4500)$. It is not compatible with a 4:2 complex (dotted line).

Sedimentation velocity studies that evaluate homogeneity/ dispersity of the same $\mathrm{COOH}$ terminus-CaM complex provide convincing evidence that the primary species $(89-95 \%$ of the total loading concentration, varying by experiment) is this very same tetrameric complex $(8.2 \mathrm{~S})$ with a minor species that represents a higher molecular weight aggregate (11.4 S) (Fig. 1E). Importantly, there is no evidence of a free $\mathrm{CaM}$ species, indicating that $\mathrm{CaM}$ is stably bound, since measurements of $\mathrm{CaM}$ alone exhibit a symmetrical sharp distribution with a standard $s$ value of $2.8 \mathrm{~S}$, compatible with the expected value for monomeric CaM (Fig. 1E). No such peak is detected in the profile of the $\mathrm{COOH}$ terminus-CaM complex. The hydrodynamic behavior of the 4:4 $\mathrm{COOH}$ terminus-CaM complex (frictional ratio $f / f_{0}=1.8$; see Ref. 29) is compatible with the solute being an elongated, nonglobular protein. Moreover, calcium is not required for this assembly, since size exclusion chromatography of a $\mathrm{COOH}$ terminus- $\mathrm{CaM}_{1234}$ complex, utilizing a CaM mutant that does not bind calcium, behaves like a $\mathrm{COOH}$ terminus-CaM $\mathrm{WT}_{\mathrm{WT}}$ complex (Fig. $\left.1 F\right)$.

CaM Organization-To explore the possibility that CaM may induce oligomerization by its association with the $\mathrm{COOH}$ terminal proximal half, we coexpressed $\mathrm{CaM}$ with a protein segment spanning helix $\mathrm{A}$ and $\mathrm{B}$ but truncated afterward $(\Delta$ helices $C$-D plus CaM) (Fig. 1, $B$ and $C$ ). Sedimentation velocity and size exclusion chromatography indicates that it behaves as a 1:1 complex of CaM to $\Delta$ helices C-D; i.e. CaM does not crosslink $\mathrm{COOH}$ terminus subunits, inducing their oligomerization 
A
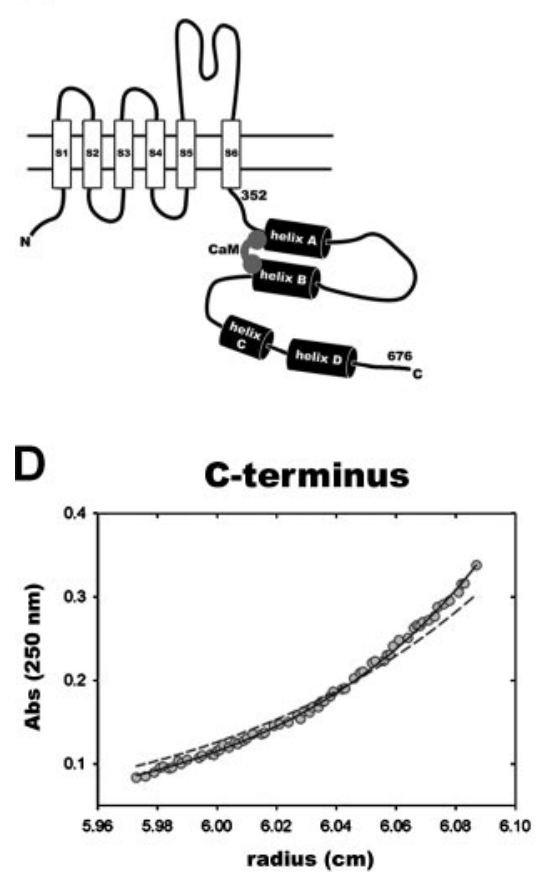

B

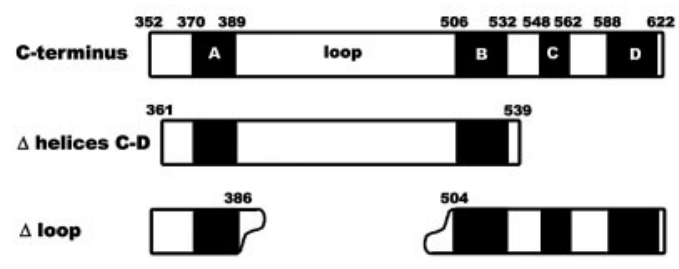

E

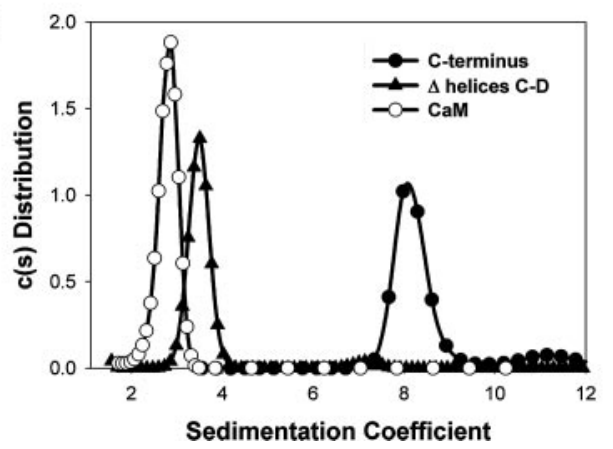

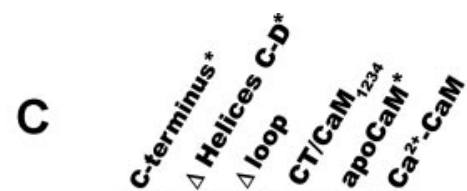

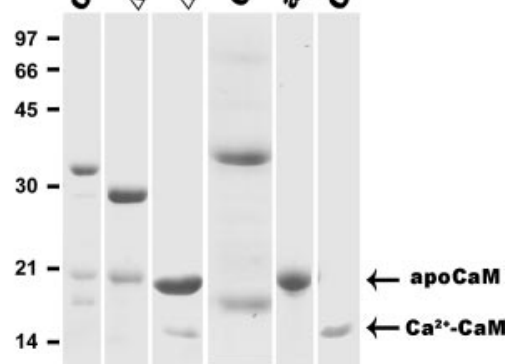

$\mathbf{F}$

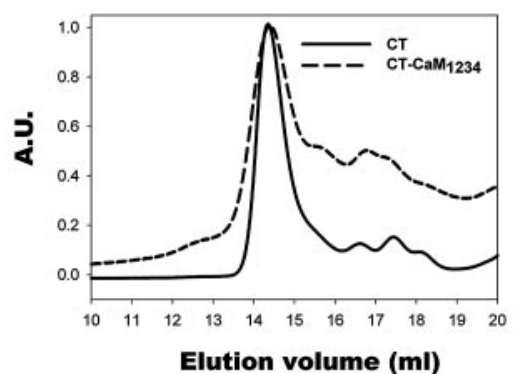

FIGURE 1. KCNQ1 COOH terminus-CaM complex structure. A, schematic diagram of KCNQ1 primary and secondary structure organization as based on sequence analysis, showing the association of CaM to helices A and B. B, schematic depiction of recombinant constructs. All of the constructs were coexpressed with CaM. C, SDS-PAGE of relevant proteins. Samples shown are composite from different gels. Samples run in the presence of 1 mM EDTA are denoted with an asterisk. The $\Delta$ loop $\mathrm{COOH}$ terminus-CaM sample was electrophoresed in the presence of $1 \mathrm{mM} \mathrm{CaCl}_{2}$ so as to facilitate separation of the two bands. $D$, sedimentation equilibrium gradient of the $\mathrm{COOH}$ terminus-CaM complex. The solid and dotted lines represent the gradient expected for a 4:4 and a 4:2 complex, respectively, whereas the gray circles represent experimental data. $E$, sedimentation velocity $c(s)$ distributions. The different distributions are indicated in the top right. Both the $\mathrm{COOH}$ terminus and $\Delta$ helices C-D are in complex with CaM. Experiments were performed at $50,000 \mathrm{rpm}$ and $10^{\circ} \mathrm{C}$. The $s$ values have been corrected to standard conditions. $F$, elution profiles from analytical size exclusion chromatography of $\mathrm{COOH}$ terminus-CaM complexes using a Superose 6 column. $\mathrm{CaM}_{1234}$ is a calmodulin mutated at all four $\mathrm{Ca}^{2+}$ binding sites, thereby abrogating $\mathrm{Ca}^{2+}$ binding. Absorbance units (A.U.) measured at 280 nm were normalized on a $0-1$ scale for each individual sample.

(Fig. $1 E$ and supplemental Fig. $1 A$ ), neither in the presence of calcium $(1 \mathrm{~mm})$ nor in its absence (5 mM EDTA). Since the intervening loop between helices $\mathrm{A}$ and $\mathrm{B}$ is long, binding by $\mathrm{CaM}$ of these two helices may be in either parallel or anti-parallel helical arrangements. Nevertheless, the loop is not necessary for CaM binding, since its removal does not prevent formation of the $\Delta$ loop-CaM complex (Fig. $1, B$ and C), consistent with an anti-parallel helix bundle as the target of CaM.

Role of the Distal COOH Terminus (Helices C and D)-Earlier studies on KCNQ have assigned regions from the distal $\mathrm{COOH}$ terminus, encompassing sequences predicted to form the two helices $C$ and D with what has been called an assembly or tetramerization domain. Both of these predicted helices are amphipathic and have varying probabilities to form coiledcoils. We tested the basic prediction of helicity for helix C. Using CD spectroscopy, we measured the spectrum of helix $C$ peptide (Fig. 2, $A$ and $B$ ). The results indicate clearly that helix $\mathrm{C}$ takes an $\alpha$-helical conformation (Fig. 2C). Having established that this module is helical, we then asked if it self-associates. Sedimentation equilibrium studies demonstrate that helix $\mathrm{C}$ peptide is dimeric and appears to undergo concentration-dependent dimer-tetramer association with a $K_{D}$ of $123 \pm 3 \mu \mathrm{M}$ (Fig. 2D). Therefore, the isolated helix $\mathrm{C}$ dimerizes, presumably by a coiled-coil interaction, as supported by reversible thermal denaturation, a property characteristic of coiled-coils (Fig. 2C, inset, and supplemental Fig. 2 for the heptad repeat assignment), while further associating as a dimer of dimers.

We then asked what helix $C$ will do in the context of the $\mathrm{COOH}$ terminus-CaM but without the confounding action of helix D. Sedimentation studies, both equilibrium and velocity, of $\mathrm{COOH}$ terminus $\Delta$ helix D-CaM (Fig. 2, $A$ and $B$ ) unambiguously demonstrate that the complex is best modeled as a dimer (i.e. two $\mathrm{COOH}$ terminus subunits bound to two CaMs with a buoyant molecular weight half that of the full-length $\mathrm{COOH}$ terminus-CaM complex) (solid line gradient in Fig. 2E). The data cannot be accommodated by a gradient expected for a $4: 4$ complex (Fig. 2E, dashed line). The hydrodynamic behavior of $\Delta$ helix D-CaM complex (s value of the main sedimenting species was $5 \mathrm{~s}$, open circles in Fig. $2 F$ ) also deviates from that expected for a rigid globular solute (frictional ratio $f / f_{o}=1.7$ ). We conclude that, like the isolated helix $\mathrm{C}$ module, helix $\mathrm{C}$ in its $\mathrm{COOH}$-terminal context directs dimerization. It seems likely that during biosynthesis of the intact channel, this dimeric module forms a dimer of dimers due to high local concentration.

To probe the function of helix $\mathrm{C}$ in a cellular context, we recorded currents from Chinese hamster ovary cells transfected with a helix $\mathrm{C}$ deletion channel construct. This 
deletion obviates functional expression (i.e. production of a detectable $\mathrm{K}^{+}$current) (Fig. 2G). The expressed protein appears to be retained intracellularly, as shown by immunocytochemical labeling and cell surface biotinylation assays (Fig. 2, $H$ and $I$, respectively).

What function does helix D perform? To address this question, we measured CD spectra of helix D peptide (residues 585-621), confirming its helical conformation (data not shown). We examined the peptide's oligomeric state using both sedimentation equilibrium and velocity. The results show a tetrameric species (single species with a molecular weight of $18,400 \pm$ 1500; see Fig. $3 A$ and supplemental Fig. $1 B$ ) over a wide range of concentrations $(10-100 \mu \mathrm{M})$ versus a monomeric one (molecular weight of 4200), proving that helix D forms a stable tetrameric coiled-coil with a globular shape (frictional ratio $f / f_{0}=$ 1.3), in contrast to helix C. Next, we purified a KCNQ1 COOH terminus $\Delta$ helix C-CaM complex (Fig. 3 , $B$ and $C$ ), allowing us to directly examine the action of helix D without the potential confounding effects of helix $C$, shown above to also self-associate. Sedimentation velocity establishes that the $\Delta$ helix C-CaM complex tetramerizes much like the WT $\mathrm{COOH}$ terminus-CaM complex (Fig. 3D). Therefore, helix $\mathrm{D}$ induces a tetramerization state upon the KCNQ1 COOH terminus, independent of the helix $\mathrm{C}$ segment.

Deletion of helix D abrogates KCNQ1 current (12), underlining its requirement for proper function. If the helix is perturbed by substitution of proline at position 609 (Ile $\rightarrow$ Pro), Roden and co-workers (15) report that no functional current is detectable, and the channel is found intracellularly. Presumably, this mutation disturbs the helix sufficiently to disrupt the predicted coiled-coil. These investigators ascribed the elimination of functional current to the essential role of helix D in trafficking the channel to the plasma membrane. We there-
A
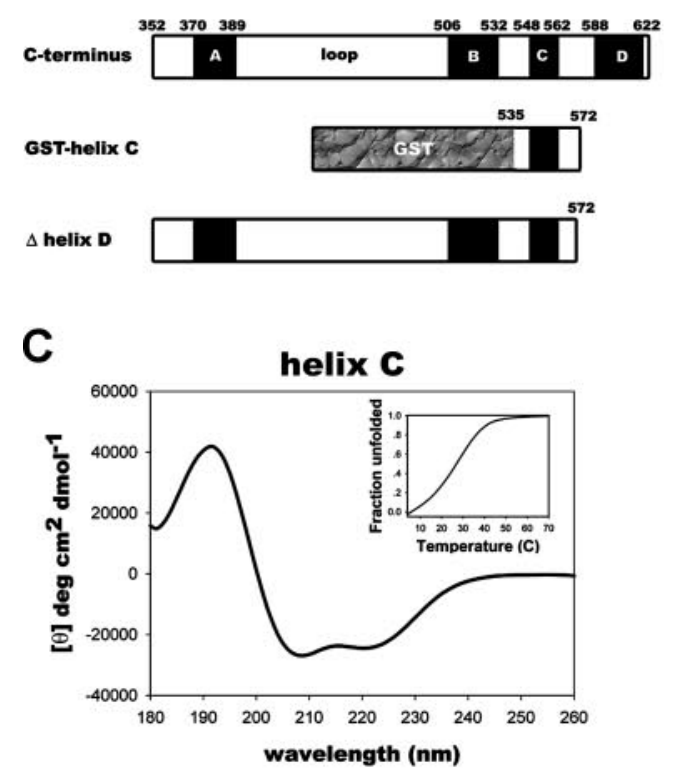

E

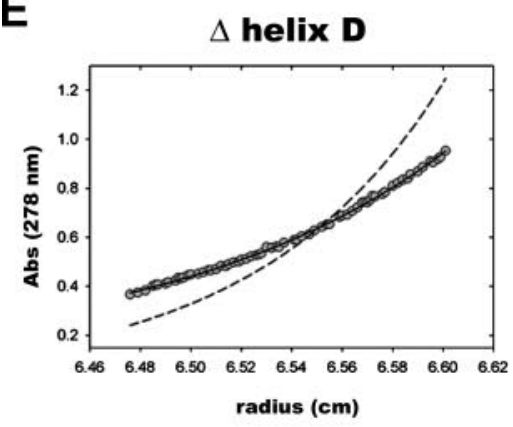

G
B

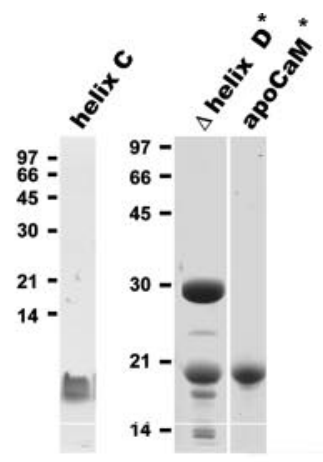

D
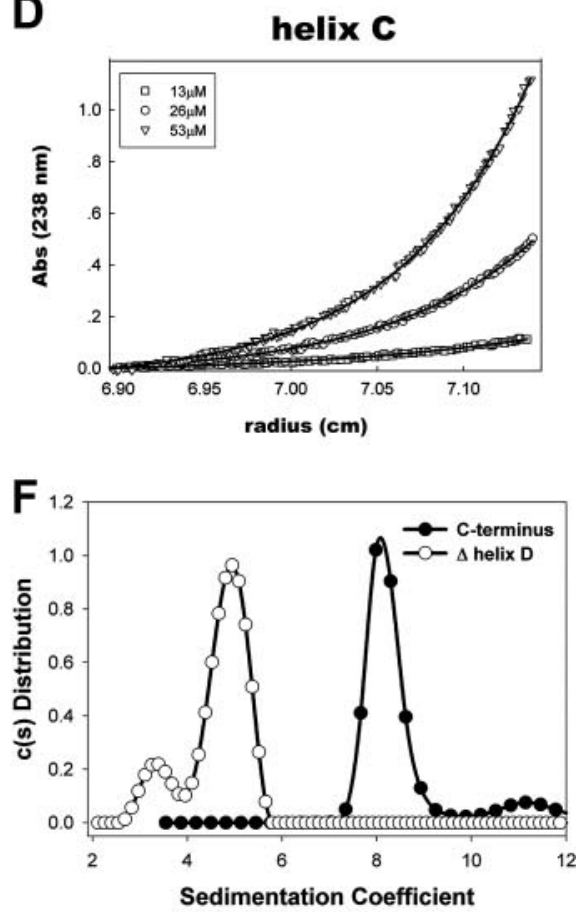

KCNQ1- $\Delta$ helix C
H

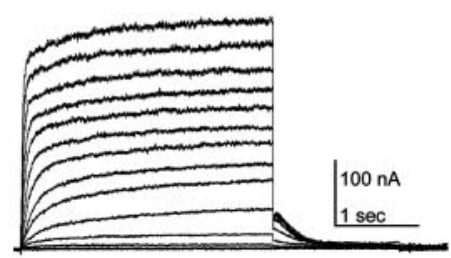

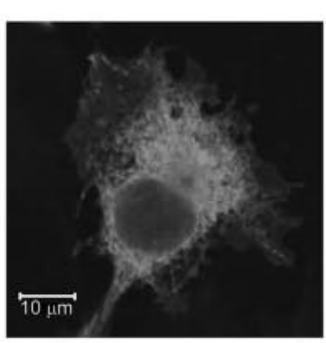
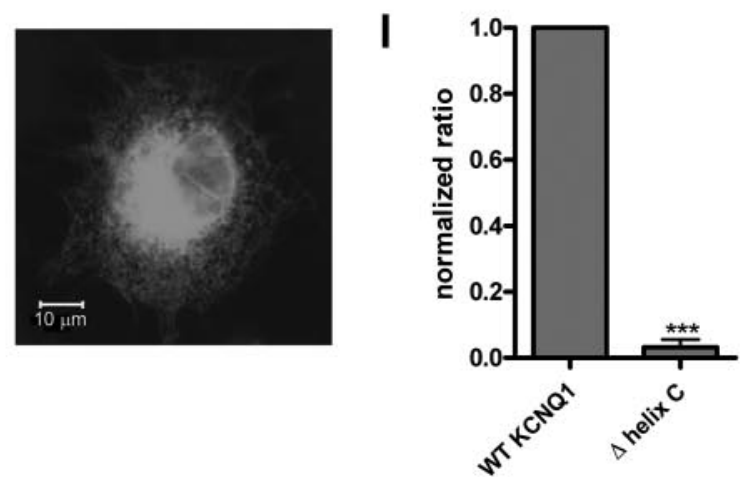
fore examined the consequences of this mutation in our expression system. The mutated protein was insoluble (data not shown), similar to that seen when $\mathrm{CaM}$ is not coexpressed or its binding sites are perturbed $(8,11)$. This result hints that viable channel folding and assembly requires properly folded helix D.

If helix D directs tetramerization, then perhaps we could replace it with an analogous coiled-coil that performs the same task. Such coiled-coils have been used in similar contexts (30). We utilized GCN4-LI, a modified GCN4 coiled-coil that forms a parallel, tetrameric coiled-coil (31). The GCN4-LI module was introduced into KCNQ1 COOH terminus at residue 594, preserving completely the first helical turn of helix D (Fig. 3B). This chimeric protein was soluble (Fig. $3 C$ ), and a fraction of it behaved like WT in sedimentation velocity experiments (Fig. $3 D$ ), corroborated by size exclusion chromatography (supplemental Fig. 1C), but when transfected into cells it produced no current and was retained intracellularly without evidence of cell surface expression (Fig. 3, E-G).

Crystallographic Studies of the Helix D Tetramer-What is the molecular mechanism by which helix D acts? We obtained the atomic details of this molecular complex using x-ray crystallography. Crystallization trials with $\mathrm{COOH}$ terminus $\Delta$ loopCaM complex (Fig. 1, $B$ and $C$ ) yielded small crystals after several weeks. $\mathrm{NH}_{2}$-terminal sequencing of the crystallized protein identified the sample as KCNQ1 starting with residue 574, just upstream of helix D. We conclude that a contaminating protease cleaved the $\Delta$ loop protein in the predicted random coil region between helices $C$ and $D$, allowing the helix $D$ assembly to crystallize. Single wavelength anomalous diffraction and multiple isomorphous replacement with anomalous scattering diffraction experiments using a selenomethionine protein crystal and a rhenium-soaked crystal, respectively, produced excellent electron density maps to $2.0-\AA$ Bragg spacings (Table 1 ). The current refined model includes KCNQ1 residues 585-621 with good stereochemistry, 52 solvent molecules, and an $R_{\text {free }}$ of $25.5 \%$. Residues $574-584$ are not observed and must be disordered.

The crystallographic studies reveal a tetrameric parallel-oriented coiled-coil quaternary structure (Fig. $4 A$ ). The crystallographic asymmetric unit contains a dimeric coiled-coil, whereupon a 2-fold crystallographic dyad generates the presumed biological tetrameric unit. Thus, formally the helix D assembly is a dimer of dimers, with pseudo-4-fold symmetry that is close to perfect C4 symmetry. The coiled-coil cylinder is $50 \AA$ long with a diameter of about $27 \AA$, composed of helices of nine turns or about four and half heptads. Coiled-coil parameterization analysis by the program TWISTER (32) shows the assembly to have the canonical heptad (7/2) repeat, left-handed supercoiling, and other Crick parameters (Table 2) with the signature of a classical tetrameric parallel coiled-coil. The buried residues of the $a$ and $d$ heptad positions maintain alternating perpendicular and parallel knobs-in-hole packing, respectively, as computed by Socket (33). The perpendicular and parallel terms refer to packing angles for the side chains, as defined by Harbury et al. (31). This arrangement was observed for GCN4-LI. The tetramer is capped at its carboxyl-terminal end with a histidine ring coordinating a metal ion (Fig. 4B).

The coiled-coil interactions constituting the hydrophobic core and the solvent-exposed residues involved in interhelical interactions are summarized schematically in Fig. 4, $C$ and $D$. The $a$ and $d$ positions of the heptad are taken by branched, apolar residues generally conserved in both the KCNQ1 orthologs and the Kv7 subfamily. Notably, helix D of KCNQ1, as seen in the structure and sequence alignment (supplemental Fig. 2), has a longer coiled-coil, by one heptad repeat or two helical turns longer than the other KCNQ members. The one exception to the branched hydrophobic residues in positions $a$ and $d$ is the capping histidine found in position $a$. Kim and co-workers (31), in studies using the dimeric GCN4 as a scaffold, proposed a set of rules for predicting the oligomeric state of a coiled-coil. They posited that unbranched $C \beta$ (Leu) residues at the $a$ position with branched $C \beta$ residues (Ile, Val) at the $d$ position will favor tetrameric assemblies. Contrary to this proposal, the tetrameric KCNQ1 helix D $d$ positions have almost as many unbranched residues as branched.

The helix D assembly buries a total of $6540 \AA^{2}$, an area typical of coiled-coil architectures, and reflects a character more akin to globular protein core than standard protein-protein interfaces. We measured the stability of this coiled-coil using thermal denaturation, assayed by CD spectroscopy (Fig. 4E). The measurements indicate a $T_{m}$ of $\sim 35^{\circ} \mathrm{C}$ with reversibility of the process. We note this seemingly low value for tetrameric coiled-coils, despite efficient interior packing $(34,35)$.

Having established the coiled-coil architecture of both helix $\mathrm{C}$ and $\mathrm{D}$ modules separately and determined their thermal stability, we examined the consequences of having them in the tandem arrangement found in the intact protein. Specifically, would the relatively low $T_{m}$ values and reversible folding/un-

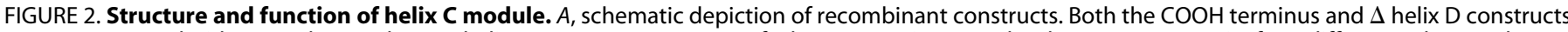

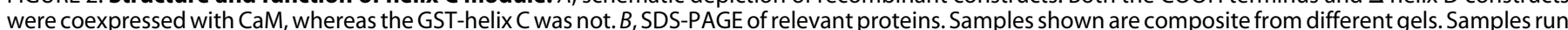

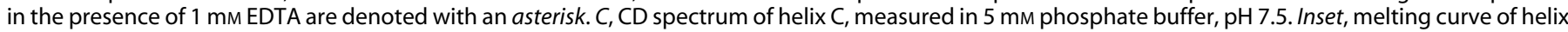

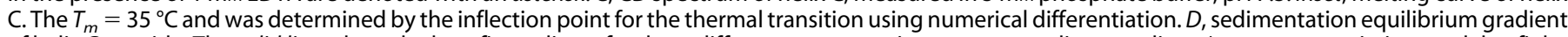

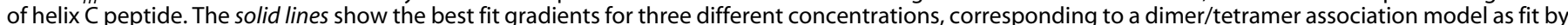

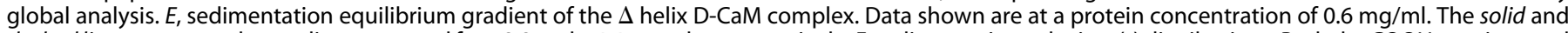

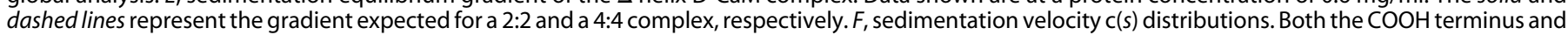

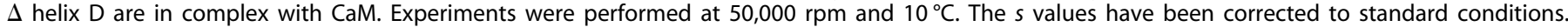

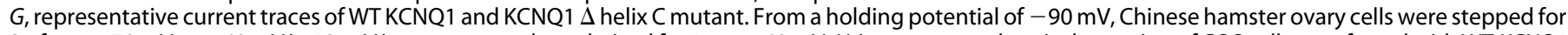

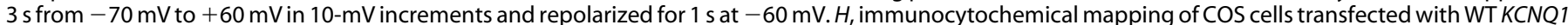

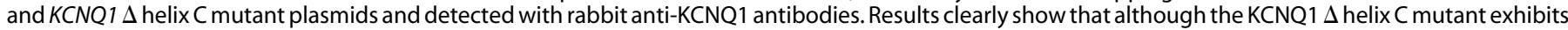

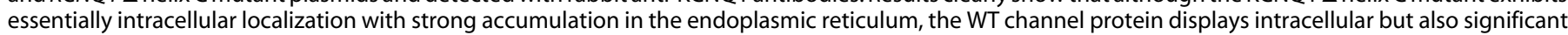

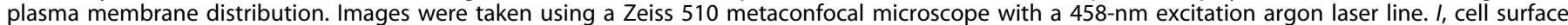

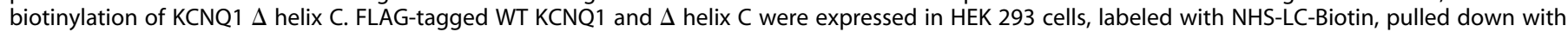

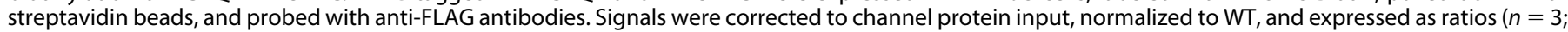
${ }^{* * *}, p<0.001$, two-tailed $t$ test). 
A

helix D

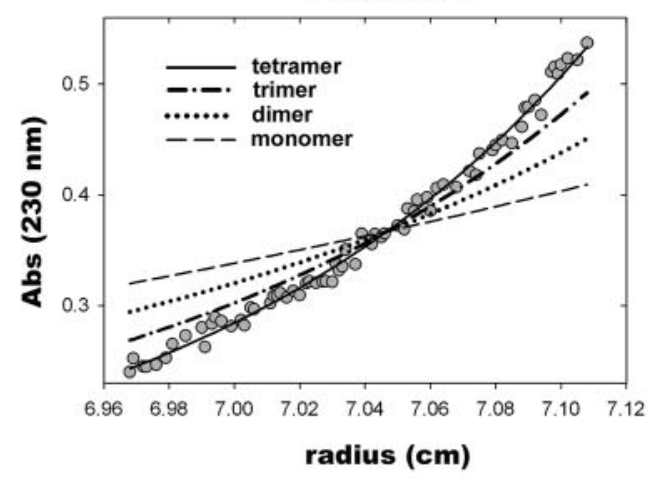

C

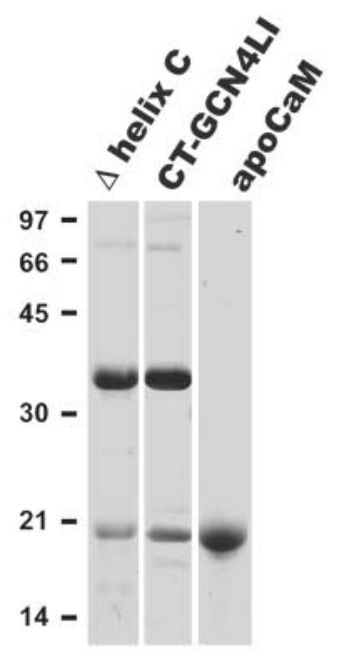

E

WT KCNQ1

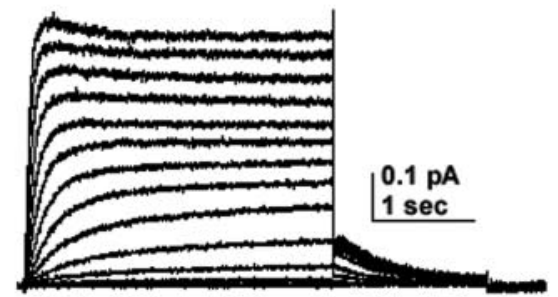

$\mathbf{F}$

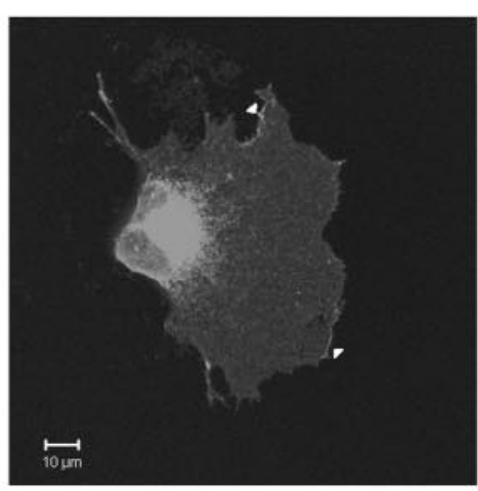

B

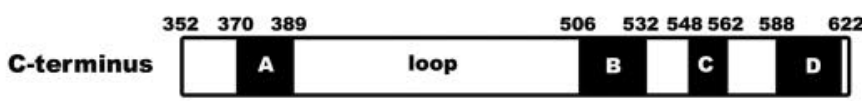

$\Delta$ helix C

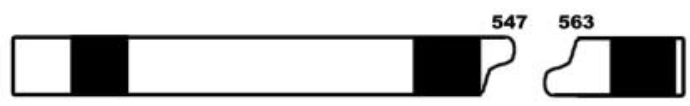

CT-GCN4LI

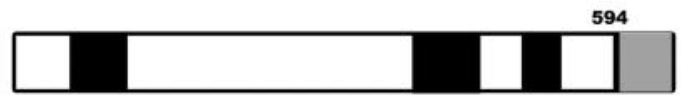

D

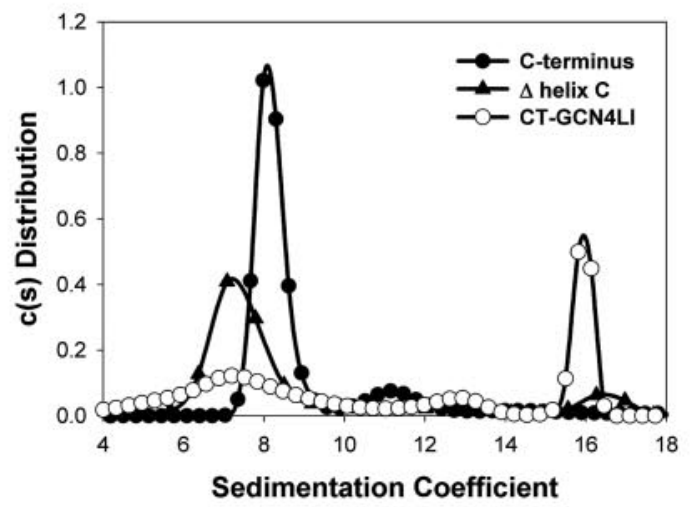

KCNQ1-GCN4LI
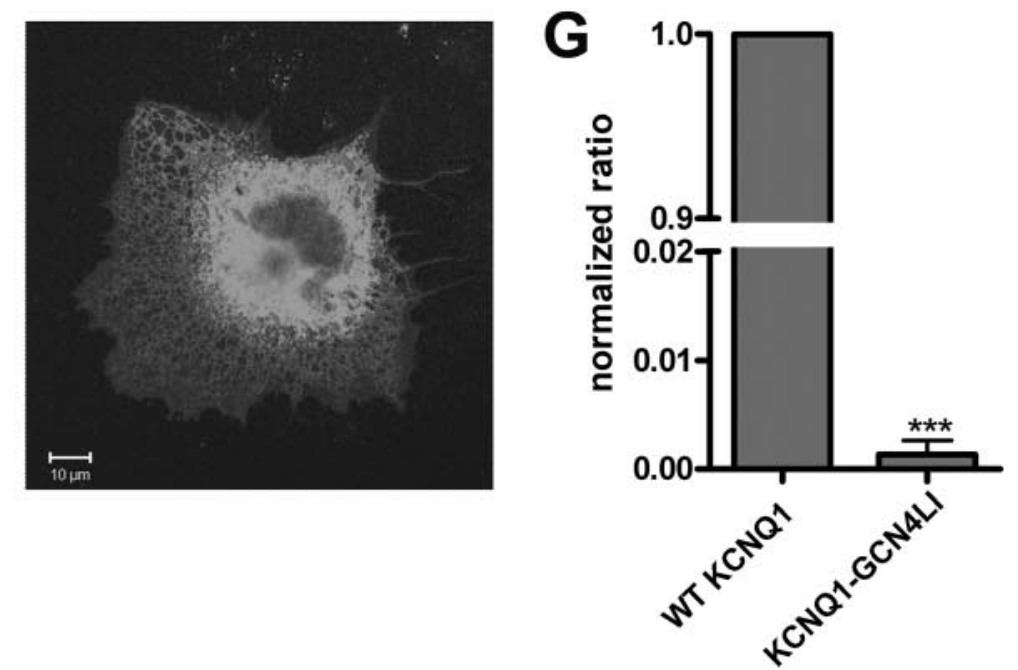


\section{Structural and Functional Studies of the KCNQ1 $\mathrm{COOH}$ Terminus}

TABLE 1

Crystallographic statistics

\begin{tabular}{|c|c|c|c|}
\hline & Native & SeMet & $\operatorname{Re}$ \\
\hline \multicolumn{4}{|l|}{ Data collection and phasing statistics } \\
\hline Wavelength $(\AA)$ & 0.9792 & 0.9788 & 0.9788 \\
\hline Space group & P3121 & P3121 & P3121 \\
\hline Unit cell parameters $(\AA ̊)$ & $a=b=51.3, c=71.1$ & $a=b=51.6, c=72.1$ & $a=b=51.4, c=71.0$ \\
\hline Total reflections & 67,168 & 131,874 & 257,557 \\
\hline Unique reflections & 7656 & 7195 & 7214 \\
\hline Completeness $(\%)^{a}$ & $99.2(99.5)$ & $96.3(99.5)$ & $99.5(100)$ \\
\hline$R_{\text {merge }}(\%)^{a, b}$ & $6.5(33.7)$ & $5.0(12.6)$ & $5.7(13.2)$ \\
\hline $\mathrm{I} / \delta^{a}$ & $19.6(3.36)$ & $47.4(21.0)$ & $52.9(26.0)$ \\
\hline Resolution range $(\AA)$ & $50-2.0$ & $50-2.5$ & $50-2.5$ \\
\hline$f / f^{\prime}$ & & $-7.6 / 4.9$ & $-7.1 / 12.1$ \\
\hline Phasing power (anomalous) & & 1.88 & 0.743 \\
\hline Phasing power (isomorphous) & & 0.743 & 0.145 \\
\hline Figure of merit & & 0.3 & \\
\hline Beamline (ESRF) & ID-29 & BM-16 & ID-14-4 \\
\hline \multicolumn{4}{|l|}{ Refinement statistics } \\
\hline No. of reflections (working/test) & & $7,283 / 354$ & \\
\hline$d_{\min }(\AA)$ & & 2.0 & \\
\hline$R_{\text {work }} / R_{\text {free }}(\%)$ & & $22.3 / 25.5$ & \\
\hline \multicolumn{4}{|l|}{ r.m.s. deviation from ideality } \\
\hline Bond lengths & & 0.008 & \\
\hline Bond angles & & 1.36 & \\
\hline$B$ factors $\left(\AA^{2}\right)$ (r.m.s. deviation of bonded atoms, main/side chain) & & $1.8 / 5.0$ & \\
\hline Average $B$ factor ( $\AA 2$ ) & & 32.3 & \\
\hline No. of protein atoms/solvent & & $642 / 52$ & \\
\hline
\end{tabular}

${ }^{a}$ Values of the highest resolution shell are given in parentheses.

${ }^{b} R_{\text {merge }}=\Sigma_{h k l} \Sigma_{i}\left|I_{h k l, i}-\langle I\rangle_{h k l}\right| / \Sigma_{h k l} \Sigma_{i}\left|I_{h k l, i}\right|$, where $I_{h k l}$ is the intensity of a reflection, and $\langle I\rangle_{h k l}$ is the average of all observations of this reflection.

folding seen for the individual modules be the same in this type of tandem organization? To this end, we constructed a GST fusion protein, beginning at helix $\mathrm{C}$ and extending to just beyond the end of helix D, which was expressed, cleaved from the GST, and purified (Fig. 4, F and G). This protein was characterized by analytical size exclusion chromatography, which suggests that it is most likely a tetrameric complex, as expected (supplemental Fig. 1D). We further analyzed the complex with CD spectroscopy, where it shows the anticipated helical structure (Fig. $4 H$ ). Thermal denaturation experiments demonstrate a more complex denaturation curve than that seen for both of the individual modules with a marked increase in the $T_{m}$ (about $45^{\circ} \mathrm{C}$ ) and two different phases in the unfolding, one in the $30-40{ }^{\circ} \mathrm{C}$ range with a later phase occurring between 55 and $65^{\circ} \mathrm{C}$ (Fig. $4 H$, inset). Moreover, the folding was not reversible. We conclude that the tandem coiled-coil architecture confers appreciable stability, including a possible kinetic deterrent to unfolding/dissociation of the distal $\mathrm{COOH}$ terminus.

From examination of the helix D complex architecture that is both elegantly simple and symmetric, we discern three pertinent molecular features. The first (i) is the interface by which each polypeptide chain folds with the others, forming the hydrophobic core of the complex, primarily but not exclusively mediated by the interior $a$ and $d$ heptad positions. The second feature (ii) is the intersubunit interface and surface that contains stereochemically specific interactions (e.g. hydrogen bond and van der Waal interactions with a special emphasis on salt bridge networks). This feature furnishes biological specificity in helix D complex formation, possibly specifying homotypic or heterotypic combinations in the Kv7 subfamily. The third feature (iii) is the solvent-accessible molecular surface available for protein-protein interactions with other proteins, which is likely to play an important role in trafficking and regulation of the channel $(15,36)$. We probed these three features with a functional survey of 17 different structure-based point mutations in the helix D region, designed to perturb relevant structural determinants (Table 3 ). Certain residues are likely to contribute to more than one molecular feature.

When we sought to disrupt the coiled-coil hydrophobic core (molecular feature i), only specific changes had an impact. We focused not just on residues of the $a$ and $d$ positions but also on buried residues from other heptad positions. For example, G589M, L602I, or I609L had no significant effect, as assessed by current recorded from transfected cells (Table 3). These results suggest a measure of plasticity in the helix D complex's folding determinants. In contrast, mutations previously performed by Roden and co-workers (15) (L606P/L613P, L606D/L613D, I609P, and L602D/I609D) that essentially abrogate cell surface

FIGURE 3. Oligomeric states and functional data of helix D module. $A$, sedimentation equilibrium gradient of helix $\mathrm{D}$ peptide. The solid line shows the best fit gradient corresponding to a tetramer, whereas the other lines denote trimer, dimer, and monomer gradients, as indicated. $B$, schematic depiction of recombinant constructs. All of the constructs were coexpressed with CaM. C, SDS-PAGE of relevant proteins. Samples shown are composite from different gels. All samples were run in the presence of $1 \mathrm{mM}$ EDTA. $D$, sedimentation velocity $c(s)$ distributions. All proteins are in complex with CaM. Experiments were done at $50,000 \mathrm{rpm}$ and $10{ }^{\circ} \mathrm{C}$. The $s$ values have been corrected to standard conditions. The estimated molecular masses for the 7.6, 12.4, and $16.3 \mathrm{~s}$ peaks are 170 , 350 , and $530 \mathrm{kDa}$, respectively. E, representative current traces of WT KCNQ1 and the KCNQ1-GCN4LI mutant. From a holding potential of -90 mV, Chinese hamster ovary cells were stepped for $3 \mathrm{~s}$ from -70 to $+60 \mathrm{mV}$ in $10-\mathrm{mV}$ increments and repolarized for $1 \mathrm{~s}$ at $-60 \mathrm{mV}$. F, immunocytochemical mapping of COS cells transfected with WT KCNQ1 and KCNQ1-GCN4LI mutant plasmids and detected with rabbit anti-KCNQ1 antibodies. Results clearly show that although the KCNQ1-GCN4LI mutant exhibits essentially intracellular localization with strong accumulation in the endoplasmic reticulum, the WT channel protein displays intracellular but also significant plasma membrane distribution, denoted by arrowheads. Images were taken using a Zeiss 510 metaconfocal microscope with a 458-nm excitation argon laser line. G, cell surface biotinylation of KCNQ1-GCN4LI. FLAG-tagged WT KCNQ1 and KCNQ1-GCN4LI fusion were expressed in HEK 293 cells, labeled with NHS-LC-Biotin, pulled down with streptavidin beads, and probed with anti-FLAG antibodies. Signals were corrected to channel protein input, normalized to WT, and expressed as ratios $\left(n=3 i^{* * *}, p<0.001\right.$, two-tailed $t$ test). 
A

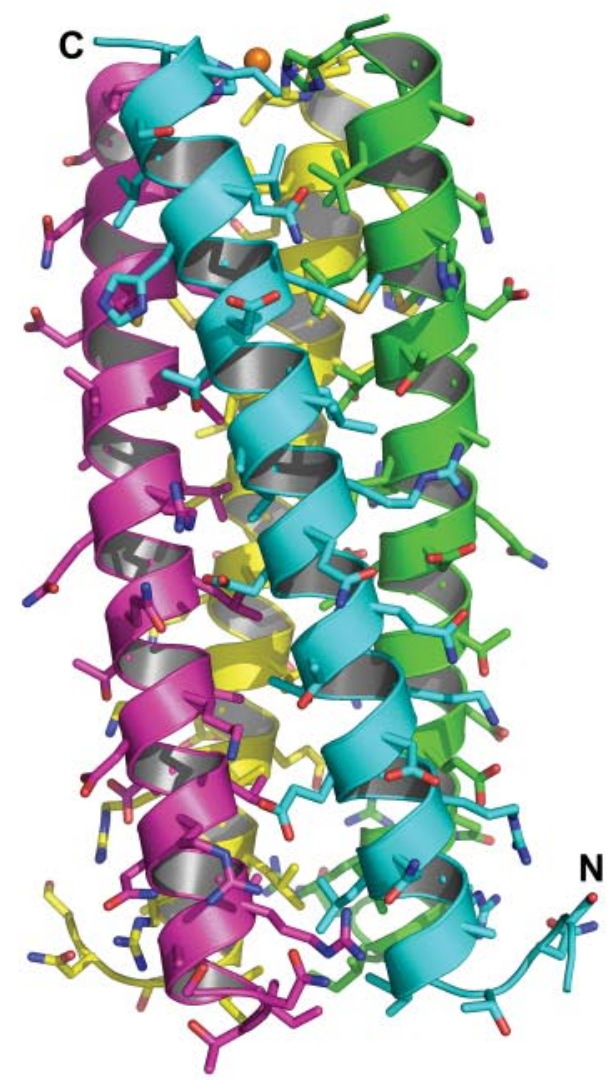

$\mathbf{E}$

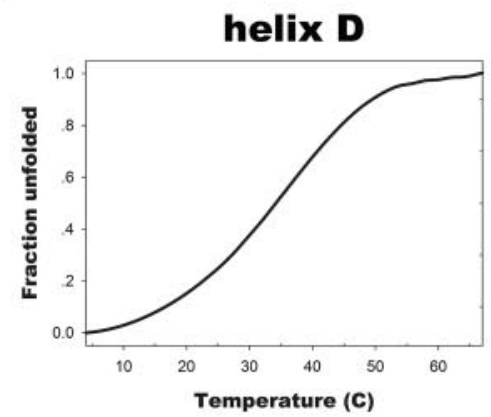

B

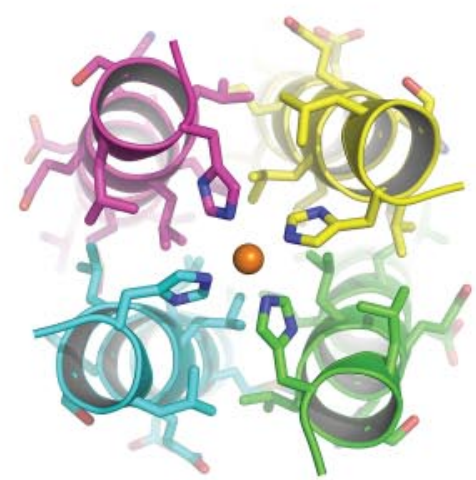

C

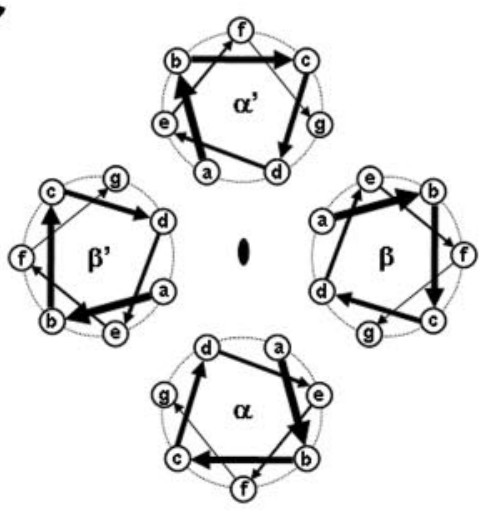

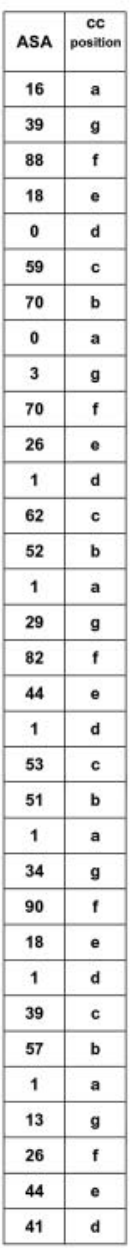

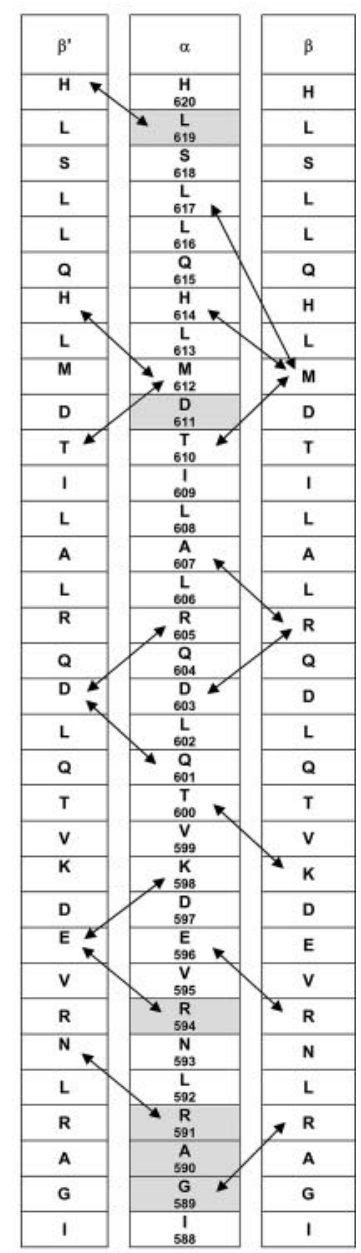

$\mathbf{F}$

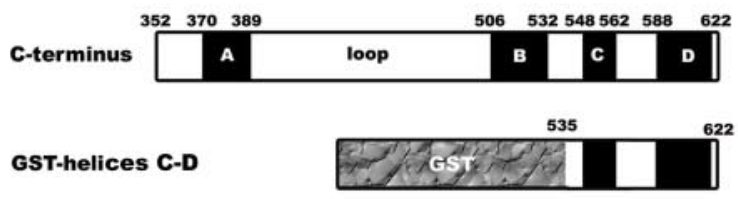

G

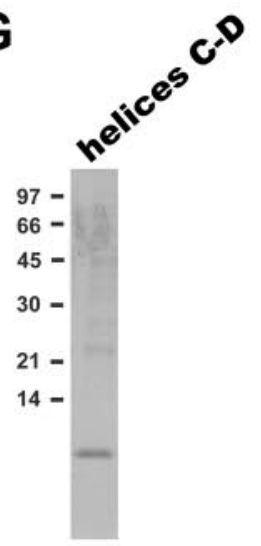

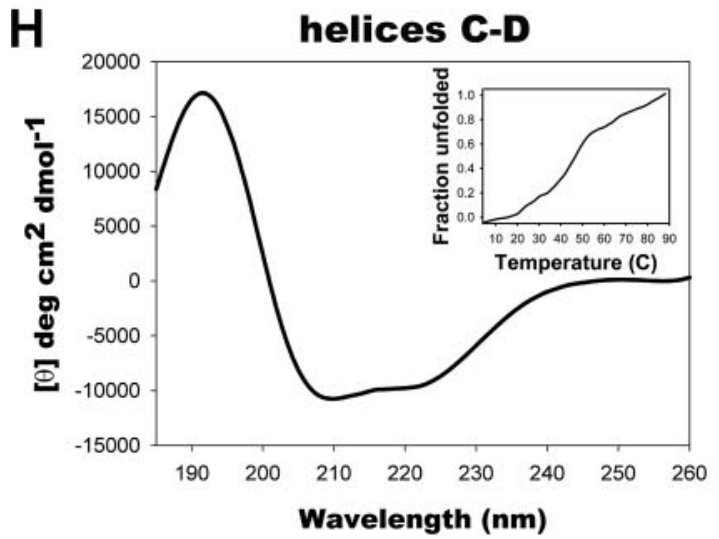


TABLE 2

Coiled-coil parameters

\begin{tabular}{cccccc}
\hline & $\begin{array}{c}\text { cc radius } \\
r_{\mathbf{0}}\end{array}$ & $\begin{array}{c}\mathrm{cc} \\
\text { pitch }\end{array}$ & $\begin{array}{c}\text { Residue } \\
\text { phase }\end{array}$ & $\begin{array}{c}\text { Residues/ } \\
\text { turn }\end{array}$ & $\begin{array}{c}\text { Rise/ } \\
\text { residue }\end{array}$ \\
\hline & $\AA$ & $\AA$ & degrees & & $\AA$ \\
KCNQ1 & 7.54 & 186.9 & $a, 19.34 ; d,-29.41$ & 3.61 & 1.5 \\
helix D & & & & & \\
GCN4-LI & 7.14 & 187.9 & $a, 20.65 ; d,-28.69$ & 3.60 & 1.52 \\
\hline
\end{tabular}

\section{TABLE 3}

\section{Electrophysiological characterization of KCNQ1 mutants}

Activation curves were fit to a Boltzmann distribution, $G / G_{\max }=1 /\left(1+\exp \left(\left(V_{50}-\right.\right.\right.$ $V) / \mathrm{s})$ ), where $V_{50}$ is the voltage at which the current is half-activated, and $s$ is the slope factor.

\begin{tabular}{|c|c|c|c|c|}
\hline Cells & $n$ & $\begin{array}{l}\mathrm{pA} \times \mathrm{pF}^{-1} \\
(\mathrm{at}+60 \mathrm{mV})\end{array}$ & $V_{50}$ & Slope \\
\hline \multicolumn{5}{|l|}{ CHO cells } \\
\hline WT & 12 & $37.3 \pm 5.4$ & $-23.6 \pm 1.3$ & $15.7 \pm 1$ \\
\hline$\Delta C$ & 4 & $2.4 \pm 0.4^{a}$ & & \\
\hline G589M & 7 & $33.2 \pm 3.6$ & $-32.5 \pm 2.0$ & $15.9 \pm 2.7$ \\
\hline G589D & 12 & $2.45 \pm 0.78^{a}$ & & \\
\hline A590W & 2 & 9.6 & & \\
\hline N593G & 6 & $20.8 \pm 2.5^{b}$ & $-11.9 \pm 8.9$ & $21.3 \pm 3.9$ \\
\hline D597K & 2 & 28.9 & $-24.0 \pm 1.6$ & $14.0 \pm 0.3$ \\
\hline T600L & 5 & $31.5 \pm 8.3$ & $-21.9 \pm 5.1$ & $28.8 \pm 4.3$ \\
\hline L602I & 5 & $32.6 \pm 4.3$ & $-28.6 \pm 2.2$ & $21.2 \pm 2.3$ \\
\hline L602M & 5 & $21.1 \pm 4.4$ & $-25.3 \pm 3.4$ & $26.1 \pm 8.3$ \\
\hline D603G & 5 & $33.1 \pm 7.1$ & $-39.3 \pm 6.2^{c}$ & $41.1 \pm 9.9^{a}$ \\
\hline H620A & 6 & $39.3 \pm 12.5$ & $-21.2 \pm 2.7$ & $31.9 \pm 9.1$ \\
\hline H620S & 5 & $21.9 \pm 6.8$ & $-13.1 \pm 1.9$ & $8.5 \pm 2.7$ \\
\hline \multicolumn{5}{|l|}{ HEK cells } \\
\hline WT & 17 & $97.5 \pm 9.1$ & $-14.3 \pm 3.0$ & $18.1 \pm 1.3$ \\
\hline D597A & 8 & $101.4 \pm 11.5$ & $-14.9 \pm 4.8$ & $22.6 \pm 2.3$ \\
\hline Q601A & 4 & $139.0 \pm 24.8$ & $-23.1 \pm 5.4$ & $23.6 \pm 3.9$ \\
\hline Q604A & 5 & $127.7 \pm 17.3$ & $-19.0 \pm 3.2$ & $21.9 \pm 0.9$ \\
\hline L608A & 4 & $147.5 \pm 24.6$ & $-31.0 \pm 9.2$ & $20.8 \pm 0.9$ \\
\hline I609L & 8 & $104.1 \pm 11.8$ & $-6.8 \pm 2.5$ & $15.9 \pm 1.9$ \\
\hline D611A & 7 & $81.7 \pm 5.1$ & $-15.1 \pm 4.8$ & $19.3 \pm 2.5$ \\
\hline Q615A & 8 & $109.6 \pm 7.4$ & $-30.5 \pm 5.6^{c}$ & $20.8 \pm 1.9$ \\
\hline \multicolumn{5}{|c|}{$\begin{array}{l}{ }^{a} p<0.01 \text { versus WT (one-way analysis of variance followed by Dunnett's multiple } \\
\text { comparison test). } \\
{ }^{b} p<0.05 \text {, unpaired two-tailed } t \text { test. } \\
c p<0.05 \text { versus WT (one-way analysis of variance followed by Dunnett's multiple } \\
\text { comparison test). }\end{array}$} \\
\hline
\end{tabular}

expression, are easily rationalized in light of the structure. All of these mutations change $a$ or $d$ heptad position hydrophobic residues to either helix-kinking proline or a negative charge, almost certainly disrupting the coiled-coil assembly. On the other hand, when these same residues were replaced by alanine in that same study, surface expression approached that of WT, underscoring the complex's plasticity. The alanine replacements are neutral; they do not negatively or positively select against heptad position partners, a principle clearly critical in coiled-coils $(33,37)$.

Hydrogen-bonded salt bridges play a prominent role in the intersubunit interface (molecular feature ii). For example, $\operatorname{Arg}^{594}$ ( $c$ position in $\alpha$ subunit) hydrogen-bonds to $\mathrm{Glu}^{596}$ ( $e$ position in $\beta$ subunit), which concomitantly engages $\operatorname{Lys}^{598}$ ( $g$ position in $\alpha$ subunit) (Fig. 4, $C$ and $D$ ). This network is typical of coiled-coils and may facilitate specificity of assembly in two ways; first, determination of the partner subunit, and second, number of subunits in the assembly. Charged residues confer specificity by requiring an oppositely charged residue to be in proximity and by selecting against a partner whose proximal residue is like charged. Nonetheless, obvious empirical rules are not easily derived, since many expected perturbations of this molecular feature like T600L, Q601A, or D603G appear to have little effect (Table 3).

To probe the importance of the complex's solvent accessible residues vis á vis their potential role to generate a platform for interacting proteins (molecular feature iii), we mutated almost all of the helix D residues with accessibility greater than $40 \%$ (Table 3). The preponderance had little or no effect. However, three mutations, G589D, A590W, and N593G, located in the $\mathrm{NH}_{2}$-terminal third of helix D reduced the expressed $\mathrm{K}^{+}$currents in the transfected cells.

KCNQ1 has been implicated genetically in long QT syndrome. Lesions responsible for this pathophysiological phenotype are found scattered over the structural gene, and several localize to helix D (supplemental Table 1). A representation showing their location on the complex's molecular surface is depicted in Fig. 5A. Strikingly, these mutations predominantly cluster in the $\mathrm{NH}_{2}$-terminal third of the assembly and include the loop upstream of the assembly, forming a contiguous surface. Curiously, all of the mutations involve non- $a$ or $d$ coiled-coil position residues. Thus, they either perturb partner specification in assembly (e.g. R594H) or formation of proteinprotein interaction interfaces or both. Apparently, they do not perturb folding and tetrameric assembly. One mutation, G589D, has been shown to abrogate binding of the A kinaseanchoring protein protein yotiao, important for sympathetic regulation of the cardiac action potential as mediated by $\beta$-adrenergic receptor signaling (36). Other possibilities could involve proteins important for trafficking of the channel complex to the plasma membrane (15).

We thus focused our characterization efforts on five point mutations of helix D that perturbed current expression, in an attempt to define their molecular mechanism. The residues' locations on the helix D coiled-coil are graphically depicted in Fig. 5B. These mutations should impinge upon the molecular features described above. Specifically, G589D, a LQT mutation, along with A590W, N593G, and possibly H620S, may affect both intersubunit interfaces and the surface available for protein-protein interactions. Mutations L602M, H620S, and possibly A590W may affect the core of the complex. The currentvoltage relations ( $I-\mathrm{V}$ curves) determined for the various mutants (Fig. 5, $C$ and $D$ ) indicate that some (N593G, L602M, and H620S) give rise to moderately impaired current magni-

FIGURE 4. Structure of the tetrameric coiled-coil helix $\mathbf{D}$ complex. $A$, ribbon depiction of the assembly with each chain colored differently from a side perspective (bottom, $\mathrm{NH}_{2}$ terminus; top, $\mathrm{COOH}$ terminus). The metal ion coordinated by the histidine ring at the $\mathrm{COOH}$-terminal end is shown as an orange sphere. $B$, top view (COOH-terminal) of the complex. $C$, a helical wheel diagram showing the crystallographic dimer of dimer organization in the tetrameric complex and the relative orientation of the heptad repeat positions. $D$, schematic diagram showing interhelical interactions in the coiled-coil. The shaded boxes indicate long QT syndrome mutations. The arrows denote hydrogen bond or van der Waals interactions. Relative accessible surface area (ASA) values (in percent) are shown for each residue as calculated by Naccess (available on the World Wide Web). E, melting curve of the helix D module. The $T_{m}$ was $35^{\circ} \mathrm{C}$ and was determined as before in Fig. 3C. The buffer used was PBS, pH 7.4. F, schematic depiction of recombinant constructs. G, SDS-PAGE of the helices C-D protein (residues 535-622). $H, C D$ spectrum of helices C-D measured in $5 \mathrm{~mm}$ phosphate buffer, pH 7.5. Inset, melting curve of helices C-D. $T_{m}$ was $\sim 45^{\circ} \mathrm{C}$ as determined by inspection, since numerical differentiation was not possible due to the curve's complexity. 
A

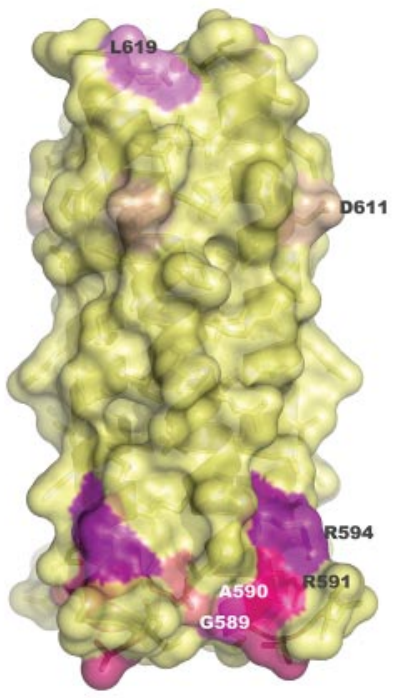

B

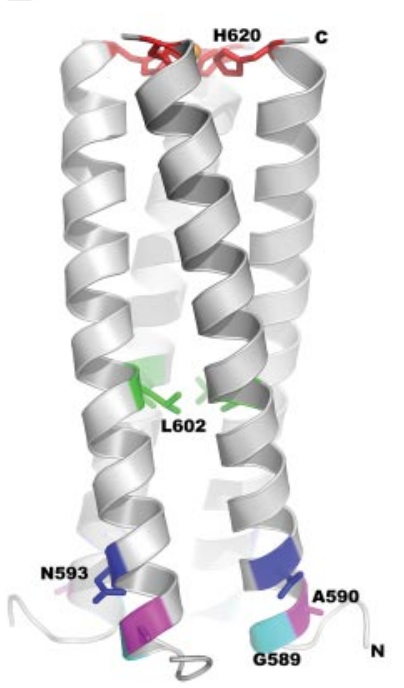

C

\section{WT}
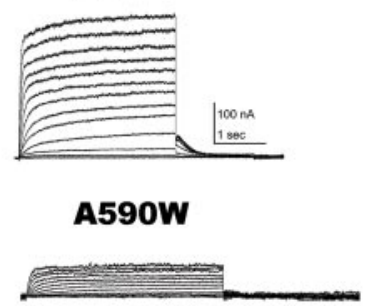

H620S
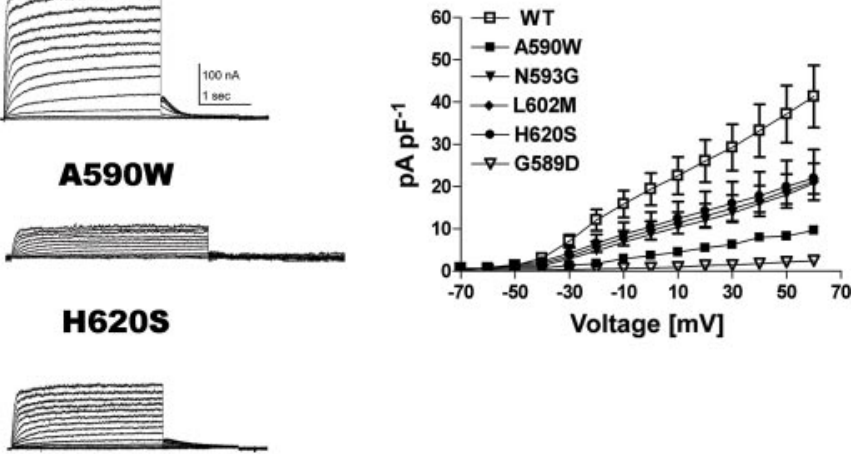

G589D

$E$
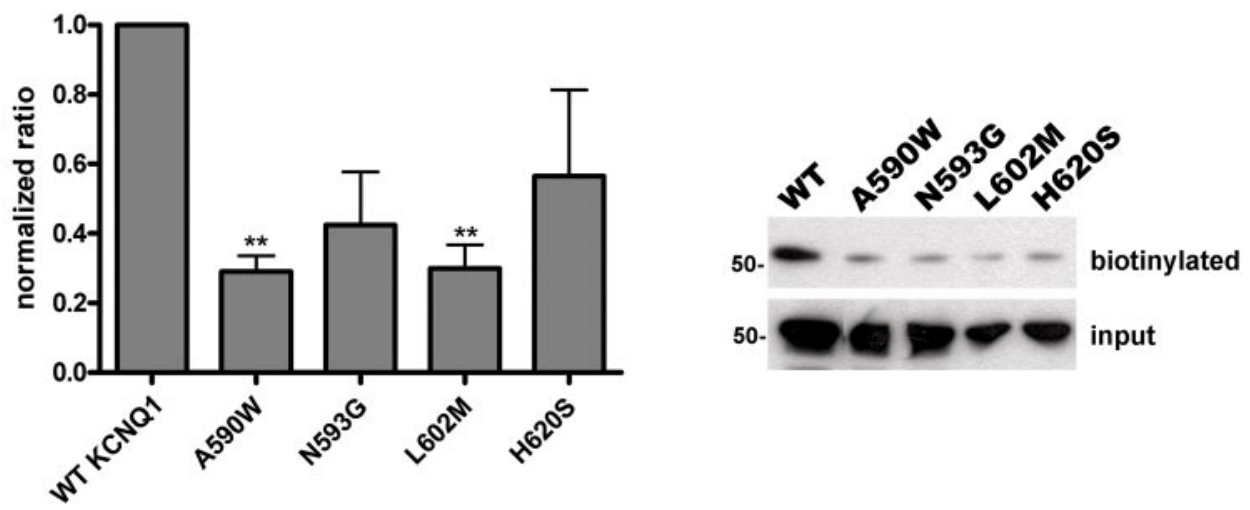

$\mathbf{F}$

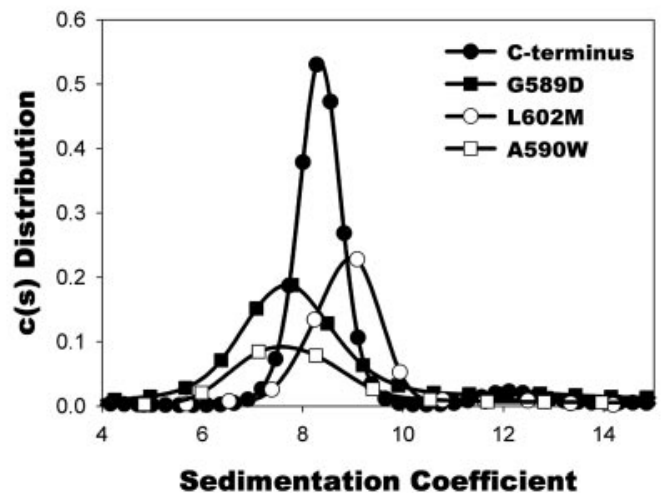

G

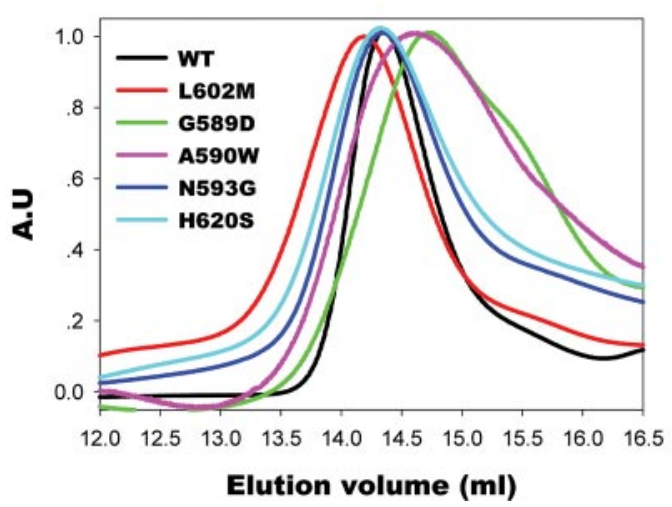

FIGURE 5. Structure-based functional studies. A, long QT syndrome mutations mapped and labeled onto the assembly's surface, colored in various shades of red. $B$, structure-based mutants mapped and labeled onto a ribbon depiction of the complex with each mutation colored differently. $C$, representative current traces of WT KCNQ1, KCNQ1-A590W, KCNQ1-H620S, and KCNQ1-G589D mutants. From a holding potential of -90 mV, Chinese hamster ovary cells were stepped for $3 \mathrm{~s}$ from -70 to $+60 \mathrm{mV}$ in $10-\mathrm{mV}$ increments and repolarized for $1 \mathrm{~s}$ at $-60 \mathrm{mV}$. D, current densities were plotted as a function of membrane potential for WT KCNQ1, A590W, G589D, N593G, L602M, and H620S ( $n=2-8$ cells). E, cell surface biotinylation of KCNQ1 point mutants. FLAG-tagged WT KCNQ1 and helix D mutants were expressed in HEK 293 cells, labeled with NHS-LC-Biotin, pulled down with streptavidin beads, and probed with anti-FLAG antibodies. Signals were corrected to channel protein input, normalized to WT, and expressed as ratios $(n=3 ; * *, p<0.01$, two-tailed $t$ test). On the right, a representative cell surface biotinylation immunoblot of FLAG-tagged WT KCNQ1 and helix D mutants is shown (top). Whole cell expression levels were also determined for each condition (bottom). F, sedimentation velocity $c(s)$ distributions. All proteins are in complex with CaM as determined by SDS-PAGE (not shown). Experiments were done at $50,000 \mathrm{rpm}$ and $10^{\circ} \mathrm{C}$. The $s$ values have been corrected to standard conditions. Both WT and mutants have approximately the same sedimentation coefficient (around 8 ), where the differences lie within the range of uncertainty of the numerical analysis used in calculating the $c(s)$ distribution. $G$, elution profiles from analytical size exclusion chromatography of various $\mathrm{COOH}$-terminal point mutant-CaM complexes using a Superose 6 column. Absorbance units (A.U.) measured at $280 \mathrm{~nm}$ were normalized on a $0-1$ scale for each individual sample.

tude, whereas the current magnitude of others (G589D and A590W) is severely diminished. Previously published reports for G589D conflict; Kass and co-workers (36) published data showing unimpaired $\mathrm{K}^{+}$currents and normal plasma membrane location, whereas Roden and co-workers demonstrated complete $\mathrm{K}^{+}$current inhibition, as we observe, and intracellu- 
ICP spectrometry of helix $D$ peptide metal binding

\begin{tabular}{|c|c|c|c|c|c|}
\hline & $\begin{array}{c}\text { Dialysis } \\
\text { buffer }\end{array}$ & $\begin{array}{l}\text { Helix D peptide } \\
\text { suspended in } \\
\text { metal mixture }\end{array}$ & $\begin{array}{l}\text { Helix D peptide } \\
\text { suspended in } \\
\text { buffer }\end{array}$ & $\begin{array}{l}\text { Control peptide } \\
\text { suspended in } \\
\text { metal mixture }\end{array}$ & $\begin{array}{l}\text { Metal } \\
\text { mixture }\end{array}$ \\
\hline & $m g / m l$ & $m g / m l$ & $m g / m l$ & $m g / m l$ & $m g / m l$ \\
\hline Calcium & $<0.6$ & $<0.6$ & $<0.6$ & $<0.6$ & 1.5 \\
\hline Copper & $<0.02$ & 0.24 & $<0.02$ & $<0.02$ & 1.76 \\
\hline Magnesium & $<0.05$ & $<0.05$ & $<0.05$ & $<0.05$ & 0.6 \\
\hline Manganese & $<0.01$ & $<0.01$ & $<0.01$ & $<0.01$ & 0.12 \\
\hline Zinc & $<0.03$ & $<0.03$ & 0.06 & $<0.03$ & 2.4 \\
\hline
\end{tabular}

lar channel retention (15). In order to determine if these mutants' current deficiency was due to problems with targeting, we performed cell surface biotinylation assays on four mutants. The results are shown in Fig. 5E. The mutants exhibit diminished but variable cell surface expression when compared with WT. To some degree, functional current expression correlates with cell surface expression.

We then asked if the mutations might be causing difficulties in assembly. We addressed this question by expressing and purifying the point mutants in complex with CaM in our recombinant system. These complexes were then studied by sedimentation velocity and/or size exclusion chromatography. The results are shown in Fig. 5, F and G. The WT COOH terminus-CaM complex provides a size and shape standard for the $4: 4$ tetrameric assembly with $\mathrm{c}(s)$ distribution centered around $8 \mathrm{~s}$. We quantitated the fraction of mutant complex that sediments at the peak corresponding to a tetrameric assembly from the derived $\mathrm{c}(s)$ distribution of each individual sedimentation velocity experiment. The mutants G589D, A590W, L602M, form 76, 69, and 71\% tetrameric assemblies, respectively, whereas the WT forms $88 \%$. Generally, the mutants exhibit more polydispersity than the WT. Based on size exclusion chromatography, the mutants N593G and H620S behaved almost exactly like the WT. We conclude that all of the mutants appear to assemble into proper tetrameric complexes, albeit with slighter lower efficiency than WT. Therefore, their lower functional expression does not stem from flawed assembly but from either faulty trafficking or other defective regulation or both.

As noted earlier, the helix D complex is capped by a histidine ring that coordinates a metal ion. This appears to be a novel structural feature not yet observed in structures from natural sequences, although similar structures have been engineered for designer coiled-coils. First, we sought to identify the metal ion. To this end, we purified, desalted, and suspended a synthetic peptide of helix D in buffer containing appropriate candidate divalent metal salts $(20 \mu \mathrm{M})$ or in buffer alone. Then samples were dialyzed extensively against buffer alone and analyzed by ICP spectrometry (Table 4). The data clearly indicate that the preferred metal ion was $\mathrm{Cu}^{2+}$. We expect that $\mathrm{Zn}^{2+}$ can bind as well (data not shown). Structurally, this identification makes good inorganic chemical sense, since $\mathrm{Cu}^{2+}$ is well suited for the observed square pyramid 5-coordination as a water molecule is bound above the metal ion. In addition, the coordination lengths are appropriate $(2.17 \AA)$. Other copperbinding proteins, such as laccase, an oxidoreductase from fungi (38), have similar stereochemistry, wherein four histidines chelate the copper.

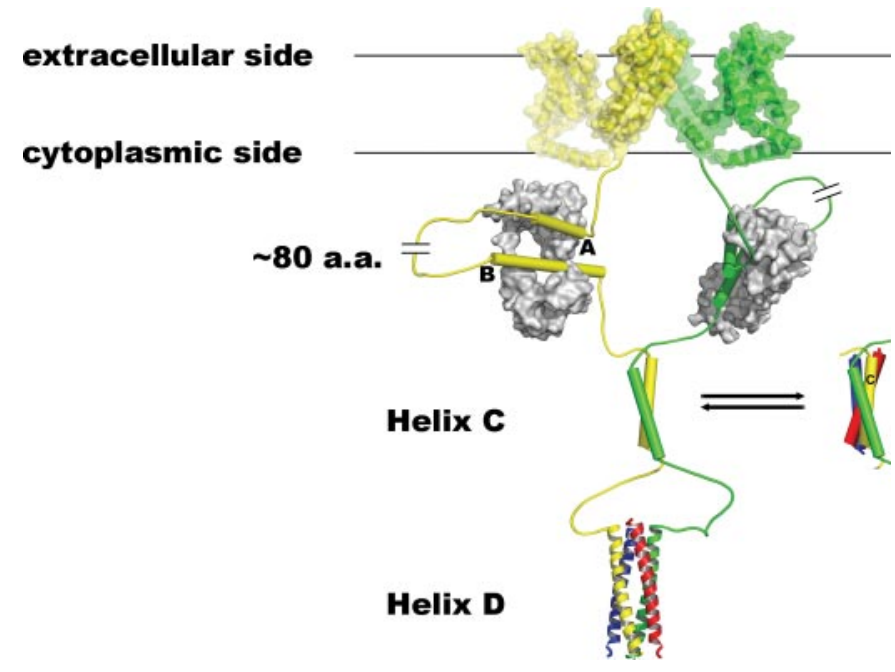

FIGURE 6. Quaternary structure model of the KCNQ1 COOH terminusCaM complex. CaM molecules have been drawn as gray surface representations, binding to helices $\mathrm{A}$ and $\mathrm{B}$ in an antiparallel manner (labels indicate amino-terminal end of the helix). It is not known if helices $A$ and $B$ are in contact with each other. The two subunits depicted are colored yellow and green. The membranous protein surfaces have been modeled using the mammalian Shaker structure (4). Only two subunits related by a dyad are depicted for clarity, and no intent is made to suggest that those subunits will actually form the dimer at helix $\mathrm{C}$. Rather, it seems more likely that neighboring subunits would form a dimer at helix C. The helix $C$ complex has been drawn to undergo dimerization of its dimeric coiled-coil, whereas the helix D complex is depicted as a stable, tetrameric parallel coiled-coil, as seen in the crystal structure. The complete blue and red chains have been omitted for clarity.

We asked if metal binding is necessary for assembly formation by using thermal denaturation as measured with $C D$. The addition of metal did not change the melting temperature, indicating no stabilizing effect. We then turned to mutagenesis and functional assays to evaluate the significance of metal binding. When we mutated the histidine 620 to alanine, no appreciable effect was seen on current recorded from transfected cells. When the histidine was changed to serine, although not significant, some inhibition $(\sim 50 \%)$ of the current was detected (Table 3 and Fig. 5, $C$ and $D$ ).

\section{DISCUSSION}

We outline our findings with a working model for the $\mathrm{KCNQ} 1 \mathrm{COOH}$ terminus structure and its functional correlates. A structural model is drawn in Fig. 6. The $\mathrm{COOH}$ terminus structure may be best summarized by dividing it into two halves, proximal and distal to the membrane. The proximal half binds CaM. The configuration of CaM association that best agrees with our data has one CaM binding by sandwiching helices A and B of a single subunit. Accordingly, CaM does not play 


\section{Structural and Functional Studies of the KCNQ1 COOH Terminus}

a direct role in oligomerization but apparently participates in forming a module, pivotal for regulating channel gating $(8,11)$. Nevertheless, apoCaM does play a critical role in correct $\mathrm{COOH}$-terminal folding, since its absence results in no functional channels and no soluble $\mathrm{COOH}$ terminus $(8,11)$, whereas $\mathrm{Ca}^{2+}$-CaM is not required, as seen from experiments using $\mathrm{CaM}_{1234}$ (Fig. 1F) (11). Also, calcium does not induce dimerization of the proximal $\mathrm{COOH}$ terminus as observed in our sedimentation velocity experiments with $\Delta$ helices C-DCaM, unlike the SK channel structure (39). Helices A and B are connected by a long stretch of polypeptide, dubbed above the intervening loop, that has little sequence conservation, regions of low complexity, and little predicted secondary structure. This intervening loop is not required for formation of the tetrameric $\mathrm{COOH}$ terminus-CaM complex (Fig. 1C).

The distal COOH-terminal half contains two tandemly arranged coiled-coils. This half directs oligomerization due to two structural components, namely the helix $\mathrm{C}$ module, the first coiled-coil that is dimeric, and subsequently the helix D module, the second coiled-coil that is tetrameric. These two components are linked by a proteolytically susceptible linker, strongly suggesting that this 22-residue span is mobile and not well structured. Two independent observations support that conclusion: first, adventitious proteolysis in this region enabled crystallization of the helix D complex from the COOH terminus $\Delta$ loop-CaM complex, and second, residues 574-586, although present in the protein, are not discernible in the electron density map.

The two coiled-coils are intrinsically different, since the helix $\mathrm{C}$ module fundamental unit appears to be dimeric, probably parallel due to structural considerations. This unit undergoes concentration-dependent self-association into a dimer of dimers. This concentration-dependent self-association may explain findings by Ghosh et al. (11) that a fraction of $\mathrm{COOH}$ terminus (truncated at residue 555)-CaM complex tetramerizes, as found by chemical cross-linking performed at $1 \mathrm{mg} / \mathrm{ml}$ protein concentration. Indeed, this truncation leaves intact a significant portion of the helix $\mathrm{C}$ module. Similarly, Schwake et al. (14) found that mutants disrupting the helix D module in KCNQ2 or -3 still afforded functional current, albeit significantly diminished, suggesting that the helix $\mathrm{C}$ module is sufficient for tetramerization. In contrast, the helix D module fundamental unit is a stable tetramer, even at lower concentrations. Despite the difference in quaternary structure, their individual thermal stabilities are about the same. Thermodynamically, both of the specific modules are less stable than engineered coiledcoils, not unlike some natural coiled-coils that have quite low melting points (40). These $T_{m}$ results may have implications for the dynamics of KCNQ1 biosynthesis and assembly. However, when they fold/unfold in their native tandem arrangement, there is increased thermal stabilization caused either by structural or kinetic reasons. Thus, the distal $\mathrm{COOH}$ terminus assembles by a concerted action of its particular modules.

Inspection of sequence conservation (supplemental Fig. 2) in the distal $\mathrm{COOH}$ terminus reveals that the helix $\mathrm{C}$ module is strongly conserved within the Kv7 subfamily, at both buried and surface-accessible residues. The buried residue conservation may emphasize a general role in promoting oligomeriza- tion, whereas the conservation of surface residues may hint at its role as a surface for associating proteins involved in trafficking and regulation. The helix D module differs in its conservation characteristics, exhibiting markedly lower overall levels within the Kv7 subfamily with the amino-terminal third more conserved, including solvent-exposed residues (non- $a$ and $d$ positions). We propose three nonexclusive possibilities for the significance of this conservation. First, the lesser Kv7 subfamily conservation is in line with a role that specifies the type of oligomerization (i.e. homotypic and/or heterotypic). Second, coiled-coils undergo folding, which may be initiated by so-called "trigger" sequences. Examples of this phenomenon have been isolated in certain coiled-coils, and a consensus sequence has been formulated (41). Other studies have shown that trigger sequences are not found in all coiled-coils (42). The KCNQ1 sequence conforms to this trigger sequence except for the first two positions (Leu $\rightarrow \mathrm{Ile}^{588}$ and Glu $\rightarrow$ Gly $^{589}$ ). Thus, the conserved $\mathrm{NH}_{2}$-terminal end may comprise a trigger sequence for helix $\mathrm{D}$ assembly. When we perturbed this sequence region (residues 588-594), removing the entire helix D sequence in our attempt to substitute helix D with GCN4-LI, as described above, the $\mathrm{COOH}$ terminus-CaM complex aggregated in a nonspecific manner (data not shown). However, when we preserved this region (residues 588-594), we were able to construct a viable chimeric $\mathrm{COOH}$ terminus-GCN4-LI (Fig. 3, B-D), emphasizing the sequence's importance for formation of the helix D complex. Third, this region generates a surface for essential interacting proteins, conservation being a hallmark of such interfaces (36). Finally, we note the relative sequence conservation of the linker between the helix C and D modules, discerned also through the prism of LQT syndrome mutations in this region (supplemental Table 1). This feature may be due to specific requirements for folding, as just described for the KCNQ1-GCN4 chimeras. Alternatively, these conserved sequences are required for other proteins to bind.

Two salient structural features may explain the observation that human KCNQ1 homotetramerizes exclusively (i.e. it is partner-specific), whereas other members can heterotetramerize or homotetramerize $(13,16)$. First, the KCNQ1 helix D should be about two helical turns longer than the other family members. This additional heptad repeat will prefer assembly with a partner of equal length and sequence in order to realize most fully its folding potential. Indeed, the recent report of the KCNQ4 helix D complex structure supports this notion (43). Second, human KCNQ1 contains a metal coordination site capping its assembly.

Regarding this latter feature, our findings lead us to posit that since the histidines are positioned at the $a$ heptad repeat position, pointing into the interior of the coiled-coil, and alanine is found frequently at the $a$ position, the assembly or folding of tetrameric helix D is maintained. However, when serine (a hydrophilic residue infrequently found at that position and incapable of coordinating a metal ion due to its short length) is introduced, assembly is affected. Therefore, the metal coordination found in helix D of human KCNQ1 may have physiological relevance by providing an additional mechanism for assembly partner specificity. A possible structural precedent for this type of mechanism is found in $\mathrm{Kv}$ channels that contain the 


\section{Structural and Functional Studies of the KCNQ1 COOH Terminus}

tetramerization domain, $\mathrm{T} 1$. In that case, certain subtypes encode a $\mathrm{Zn}^{2+}$ binding motif that determines partner subtype specificity (44). Further experimentation will be required to test whether metal coordination may indeed be a KCNQ1 specificity determinant.

Both of the helix C and D modules in KCNQ1 are nonredundant at the functional level, although structurally there may be a degree of overlap. Our cellular studies show that the function of helix $\mathrm{C}$ is complex, since a construct like $\Delta$ helix $\mathrm{C}$, despite its apparent biochemical viability, failed to reach the plasma membrane, implying that helix $C$ plays a role in channel trafficking (Fig. 2, G-I). Hence, we assign it as a module for proper assembly and trafficking to the plasma membrane. Our experiments with helix D clearly demonstrate that it encodes a complex function also. Thus, the tetramerization functionality could be replaced in part on the biochemical level with GCN4-LI but is insufficient for functional expression, suggesting a role in trafficking, implicitly by association of proteins to this region (15). Our analysis of helix D point mutants (e.g. A590W) that demonstrate an ability to assemble to levels approaching that of WT nonetheless shows impaired functional expression, attributable in part to faulty trafficking. We speculate that such mutations may perturb binding surfaces required for association of trafficking or regulatory proteins, particularly in the amino-terminal region of the helix D module. Such an interpretation may also explain the mechanism for LQT mutations (e.g. G589D) in this region.

What does the $\mathrm{COOH}$ terminus do? T1, the intracellular domain amino-terminal to the membrane domain in several $\mathrm{KV}$ channel subfamilies, is not essential for Kv1 and Shaker channel formation. Jan and co-workers (30) suggested that it enhances channel assembly by increasing the local concentration of subunits in a multistep process. Inherent to this hypothesis is the premise that another oligomerization element exists that resides in the membrane domain of the protein. T1 then improves quaternary structure formation efficiency. In contrast, KCNQ1 channel formation cannot be coaxed out of truncations lacking its $\mathrm{COOH}$ terminus. Once again, the membrane domain must contribute considerably to channel assembly but is not sufficient. The $\mathrm{COOH}$ terminus must provide the necessary energy deficit for assembly. We propose that the helix $\mathrm{C}$ module may contribute adequate free energy for this deficit at some level, thereby creating a dimer of dimers, although this may vary from Kv7 subfamily member to member (14). Although this role might explain its outstanding conservation, this functionality is not sufficient for full maturation of the channel. To fully specify the correct partners for the tetramer and also stabilize oligomerization, the tetrameric helix D module is required. A similar functional architecture has been shown for the related EAG family of potassium channels (45). Previous and present results intimate that it provides a proteinprotein interaction platform for trafficking and regulation, in some measure analogous to $\mathrm{T} 1$. Consequently, the whole $\mathrm{COOH}$ terminus constitutes an elongated, nonglobular, multitiered scaffold for associating proteins like CaM and others central to the signaling process (46).

Finally, the layering, physically, of oligomerization predicts a staged channel assembly, whose temporal sequence at this point remains unknown. The use of coiled-coils in channel assembly perforce couples folding (i.e. tertiary structure formation) with oligomerization (i.e. quaternary structure formation), parallel to conclusions drawn by Deutsch and Robinson (47) regarding the biosynthesis of $\mathrm{Kv}$ channels that employ T1.

Acknowledgments - We thank the staff of beamlines ID29 and BM16 at the ESRF for assistance with diffraction experiments. We acknowledge the service of the Yale Keck protein core laboratory for $\mathrm{NH}_{2}$ terminal sequencing and the Hebrew University (Rehovot) interdepartmental equipment center for the ICP spectrometry analysis. Thanks go to Rachelle Gaudet and Nir Ben-Tal for critical readings of the manuscript.

\section{REFERENCES}

1. Jentsch, T. J. (2000) Nat. Rev. Neurosci. 1, 21-30

2. Robbins, J. (2001) Pharmacol. Ther. 90,1-19

3. Jentsch, T. J., Hubner, C. A., and Fuhrmann, J. C. (2004) Nat. Cell Biol. 6, $1039-1047$

4. Long, S. B., Campbell, E. B., and Mackinnon, R. (2005) Science 309, 897-903

5. Abbott, G. W., and Goldstein, S. A. (2001) Mol. Interv. 1, 95-107

6. Yus-Najera, E., Santana-Castro, I., and Villarroel, A. (2002) J. Biol. Chem. 277, 28545-28553

7. Wen, H., and Levitan, I. B. (2002) J. Neurosci. 22, 7991-8001

8. Shamgar, L., Ma, L., Schmitt, N., Haitin, Y., Peretz, A., Wiener, R., Hirsch, J., Pongs, O., and Attali, B. (2006) Circ. Res. 98, 1055-1063

9. Gamper, N., Stockand, J. D., and Shapiro, M. S. (2003) J. Neurosci. 23, $84-95$

10. Gamper, N., Li, Y., and Shapiro, M. S. (2005) Mol. Biol. Cell 16, 3538 -3551

11. Ghosh, S., Nunziato, D. A., and Pitt, G. S. (2006) Circ. Res. 98, 1048 -1054

12. Schmitt, N., Schwarz, M., Peretz, A., Abitbol, I., Attali, B., and Pongs, O. (2000) EMBO J. 19, 332-340

13. Schwake, M., Jentsch, T. J., and Friedrich, T. (2003) EMBO Rep. 4, 76-81

14. Schwake, M., Athanasiadu, D., Beimgraben, C., Blanz, J., Beck, C., Jentsch, T. J., Saftig, P., and Friedrich, T. (2006) J. Neurosci. 26, 3757-3766

15. Kanki, H., Kupershmidt, S., Yang, T., Wells, S., and Roden, D. M. (2004) J. Biol. Chem. 279, 33976-33983

16. Maljevic, S., Lerche, C., Seebohm, G., Alekov, A. K., Busch, A. E., and Lerche, H. (2003) J. Physiol. 548, 353-360

17. Schuck, P. (2000) Biophys. J. 78, 1606-1619

18. van Holde, K. E. (1986) in Physical Biochemistry, 2nd Ed., pp. 110-136, Prentice-Hall, Englewood Cliffs, NJ

19. Laue, T. M., Shah, B. D., Ridgeway, T. M., and Pelletier, S. L. (1992) in Analytical Ultracentrifugation in Biochemistry and Polymer Science (Harding, S. E., Rowe, A. J., and Horton, J. C., eds) pp. 90-125, Royal Society of Chemistry, Cambridge, UK

20. Cole, J. L. (2004) Methods Enzymol. 384, 212-232

21. Rivas, G., Stafford, W., and Minton, A. P. (1999) Methods 19, 194-212

22. Minton, A. P. (1994) in Modern Analytical Ultracentrifugation (Schuster, T. M., and Laue, T. M., eds) pp. 81-93, Birkhauser, Boston, MA

23. Otwinowski, Z., and Minor, W. (1997) Methods Enzymol. 276, 307-326

24. Brunger, A. T., Adams, P. D., Clore, G. M., DeLano, W. L., Gros, P., Grosse-Kunstleve, R. W., Jiang, J. S., Kuszewski, J., Nilges, M., Pannu, N. S., Read, R. J., Rice, L. M., Simonson, T., and Warren, G. L. (1998) Acta Crystallogr. Sect. D Biol. Crystallogr. 54, 905-921

25. de La Fortelle, E., and Bricogne, G. (1997) Methods Enzymol. 276, 472-494

26. Abrahams, J. P., and Leslie, A. G. W. (1996) Acta Crystallogr. Sect. D Biol. Crystallogr. 52, 30-42

27. Morris, R. J., Perrakis, A., and Lamzin, V. S. (2003) Methods Enzymol. 374, $229-244$

28. Murshudov, G. N., Vagin, A. A., and Dodson, E. J. (1997) Acta Crystallogr. Sect. D Biol. Crystallogr. 53, 240-255 


\section{Structural and Functional Studies of the KCNQ1 $\mathrm{COOH}$ Terminus}

29. Waxman, E., Laws, W. R., Laue, T. M., Nemerson, Y., and Ross, J. B. (1993) Biochemistry 32, 3005-3012

30. Zerangue, N., Jan, Y. N., and Jan, L. Y. (2000) Proc. Natl. Acad. Sci. U. S. A. 97, 3591-3595

31. Harbury, P. B., Zhang, T., Kim, P. S., and Alber, T. (1993) Science 262, 1401-1407

32. Strelkov, S. V., and Burkhard, P. (2002) J. Struct. Biol. 137, 54-64

33. Walshaw, J., and Woolfson, D. N. (2001) J. Mol. Biol. 307, 1427-1450

34. Kleywegt, G. J., and Jones, T. A. (1994) Acta Crystallogr. Sect. D Biol. Crystallogr. 50, 178-185

35. Fleming, P. J., and Richards, F. M. (2000) J. Mol. Biol. 299, 487-498

36. Marx, S. O., Kurokawa, J., Reiken, S., Motoike, H., D’Armiento, J., Marks, A. R., and Kass, R. S. (2002) Science 295, 496-499

37. Woolfson, D. N. (2005) Adv. Protein Chem. 70, 79-112

38. Ducros, V., Brzozowski, A. M., Wilson, K. S., Brown, S. H., Ostergaard, P., Schneider, P., Yaver, D. S., Pedersen, A. H., and Davies, G. J. (1998) Nat. Struct. Biol. 5, 310-316
39. Schumacher, M. A., Rivard, A. F., Bachinger, H. P., and Adelman, J. P. (2001) Nature 410, 1120-1124

40. Mason, J. M., Schmitz, M. A., Muller, K. M., and Arndt, K. M. (2006) Proc. Natl. Acad. Sci. U. S. A. 103, 8989-8994

41. Kammerer, R. A., Schulthess, T., Landwehr, R., Lustig, A., Engel, J., Aebi, U., and Steinmetz, M. O. (1998) Proc. Natl. Acad. Sci. U. S. A. 95, 13419-13424

42. Lee, D. L., Lavigne, P., and Hodges, R. S. (2001) J. Mol. Biol. 306, 539-553

43. Howard, R. J., Clark, K. A., Holton, J. M., and Minor, D. L., Jr. (2007) Neuron 53, 663-675

44. Bixby, K. A., Nanao, M. H., Shen, N. V., Kreusch, A., Bellamy, H., Pfaffinger, P. J., and Choe, S. (1999) Nat. Struct. Biol. 6, 38-43

45. Jenke, M., Sanchez, A., Monje, F., Stuhmer, W., Weseloh, R. M., and Pardo, L. A. (2003) EMBO J. 22, 395- 403

46. Kass, R. S., Kurokawa, J., Marx, S. O., and Marks, A. R. (2003) Trends Cardiovasc. Med. 13, 52-56

47. Robinson, J. M., and Deutsch, C. (2005) Neuron 45, 223-232 
Supplemental Table 1

\section{Long QT Syndrome mutations}

\begin{tabular}{|c|c|c|c|c|c|c|}
\hline Nucleotide & Residue & Mutation & Syndrome & $\begin{array}{c}\text { Electro- } \\
\text { physiology } \\
\text { (inhibition) }\end{array}$ & cc position & Reference \\
\hline C1637T & S546L & Missense & RWS & & & $(1)$ \\
\hline С1663T & R555C & Missense & RWS & $\begin{array}{c}75 \%, \\
\text { right shift in } \\
\text { voltage } \\
\text { activation }\end{array}$ & g & $(2,3)$ \\
\hline G1664A & $\mathrm{R} 555 \mathrm{H}$ & Missense & $\begin{array}{c}\text { RWS, } \\
\text { neonatal }\end{array}$ & & g & (4) \\
\hline A1669G & K557E & Missense & RWS & & $\mathrm{b}$ & $(5)$ \\
\hline G1685T & R562M & Missense & RWS & & $g$ & (6) \\
\hline C1697T & S566F & Missense & RWS & & & (7) \\
\hline C1697A & S566Y & Missense & RWS & & & (8) \\
\hline T1700G & I567S & Missense & RWS & & & (1) \\
\hline G1703C & G568A & Missense & RWS & & & (9) \\
\hline C1747T & R583C & Missense & $\begin{array}{l}\text { RWS; } \\
\text { DITdP }\end{array}$ & $>50 \%$ & & $(7,10)$ \\
\hline G1748A & $\mathrm{R} 583 \mathrm{H}$ & Missense & RWS & & & $(11)$ \\
\hline С1760T & T587M & Missense & $\begin{array}{l}\text { RWS, } \\
\text { JLNS }\end{array}$ & & & $(9,12,13)$ \\
\hline G1766A & G589D & Missense & RWS/JLN & $>85 \%$ & $\mathrm{e}$ & $(14-16)$ \\
\hline G1768A & A590T & Missense & RWS & & $f$ & (4) \\
\hline G1772A & $\mathrm{R} 591 \mathrm{H}$ & Missense & RWS & & $g$ & (13) \\
\hline G1781A & R594Q & Missense & RWS & $>90 \%$ & $\mathrm{C}$ & $(5,7,17)$ \\
\hline G1831T & D611Y & Missense & RWS & $\begin{array}{l}\text { change in } \\
\text { kinetics }\end{array}$ & $f$ & (18) \\
\hline T1855A & L619M & Missense & RWS & & $g$ & (8) \\
\hline G1876A & G626S & Missense & RWS & & & (8) \\
\hline
\end{tabular}

\section{Red background indicates helix C (light shaded) and helix D (dark shaded).}

1. Choi, G., Kopplin, L. J., Tester, D. J., Will, M. L., Haglund, C. M., and Ackerman, M. J. (2004) Circulation 110, 2119-2124

2. Donger, C., Denjoy, I., Berthet, M., Neyroud, N., Cruaud, C., Bennaceur, M., Chivoret, G., Schwartz, K., Coumel, P., and Guicheney, P. (1997) Circulation 96, 2778-2781

3. Chouabe, C., Neyroud, N., Guicheney, P., Lazdunski, M., Romey, G., and Barhanin, J. (1997) Embo J 16, 5472-5479

4. $\quad$ Lupoglazoff, J. M., Denjoy, I., Villain, E., Fressart, V., Simon, F., Bozio, A., Berthet, M., Benammar, N., Hainque, B., and Guicheney, P. (2004) J Am Coll Cardiol 43, 826-830

5. Jongbloed, R., Marcelis, C., Velter, C., Doevendans, P., Geraedts, J., and Smeets, H. (2002) Hum Mutat 20, 382-391 
6. Van Langen, I. M., Birnie, E., Alders, M., Jongbloed, R. J., Le Marec, H., and Wilde, A. A. (2003) J Med Genet 40, 141-145

7. Splawski, I., Shen, J., Timothy, K. W., Lehmann, M. H., Priori, S., Robinson, J. L., Moss, A. J., Schwartz, P. J., Towbin, J. A., Vincent, G. M., and Keating, M. T. (2000) Circulation 102, 1178-1185

8. Tester, D. J., Will, M. L., Haglund, C. M., and Ackerman, M. J. (2005) Heart Rhythm 2, 507-517

9. Chen, S., Zhang, L., Bryant, R. M., Vincent, G. M., Flippin, M., Lee, J. C., Brown, E., Zimmerman, F., Rozich, R., Szafranski, P., Oberti, C., Sterba, R., Marangi, D., Tchou, P. J., Chung, M. K., and Wang, Q. (2003) Clin Genet 63, 273-282

10. Yang, P., Kanki, H., Drolet, B., Yang, T., Wei, J., Viswanathan, P. C., Hohnloser, S. H., Shimizu, W., Schwartz, P. J., Stanton, M., Murray, K. T., Norris, K., George, A. L., Jr., and Roden, D. M. (2002) Circulation 105, 1943-1948

11. Kanters, J. K., Fanoe, S., Larsen, L. A., Bloch Thomsen, P. E., Toft, E., and Christiansen, M. (2004) Heart Rhythm 1, 285-292

12. Itoh, T., Tanaka, T., Nagai, R., Kikuchi, K., Ogawa, S., Okada, S., Yamagata, S., Yano, K., Yazaki, Y., and Nakamura, Y. (1998) Hum Genet 103, 290-294

13. Neyroud, N., Richard, P., Vignier, N., Donger, C., Denjoy, I., Demay, L., Shkolnikova, M., Pesce, R., Chevalier, P., Hainque, B., Coumel, P., Schwartz, K., and Guicheney, P. (1999) Circ Res 84, 290-297

14. Piippo, K., Swan, H., Pasternack, M., Chapman, H., Paavonen, K., Viitasalo, M., Toivonen, L., and Kontula, K. (2001) J Am Coll Cardiol 37, 562-568

15. Marx, S. O., Kurokawa, J., Reiken, S., Motoike, H., D'Armiento, J., Marks, A. R., and Kass, R. S. (2002) Science 295, 496-499

16. Kanki, H., Kupershmidt, S., Yang, T., Wells, S., and Roden, D. M. (2004) J Biol Chem 279, 33976-33983

17. Huang, L., Bitner-Glindzicz, M., Tranebjaerg, L., and Tinker, A. (2001) Cardiovasc Res 51, 670-680

18. Yamaguchi, M., Shimizu, M., Ino, H., Terai, H., Hayashi, K., Kaneda, T., Mabuchi, H., Sumita, R., Oshima, T., Hoshi, N., and Higashida, H. (2005) Clin Sci (Lond) 108, 143-150 
Supplementary figure legends

Figure 1. A. Elution profiles from analytical size-exclusion chromatography of Cterminus/CaM and $\Delta$ helices C-D/CaM complexes using a Superose 6 column. Absorbance units (280 nm) were normalized on 0 to 1 scale for each individual sample. Inset, standard curve used to calculate molecular weight of eluted protein complexes. B. Sedimentation velocity c(s) distribution of the helix D module, showing monodispersity. Experiments were done at $50000 \mathrm{rpm}$ and $10^{\circ} \mathrm{C}$. The s-values have been corrected to standard conditions. C. Elution profiles from analytical size-exclusion chromatography of C-terminus/CaM and C-terminus-GCN4-LI/CaM complexes using a Superose 6 column. Absorbance units (280 nm) were normalized on 0 to 1 scale for each individual sample. D. Analytical size-exclusion chromatography of helices C-D protein complex (residues 535-622, drawn as an open square symbol) using a Superdex 75 column. The number above the open square indicates the multiple of a single helices C-D protein mass. Molecular weight standards are drawn as filled circles. Size-exclusion chromatography measures hydrodynamic shape and not absolute mass. Hence, we interpret the helices CD protein complex elution volume to be more consistent with a tetramer, not a pentamer, due to the complex's expected elongated shape, unlike the globular molecular weight standards.

Figure 2. KCNQ1 ortholog and paralog sequence alignment of the C-terminus. Sequences of KCNQ1 orthologs from six species (SQUAC - spiny dogfish [Squalus acanthias]; beetle [Tribolium castaneum]) and human Kv7 paralogs were aligned using Tcoffee (1). Helical secondary structure is denoted by cylinders drawn above the appropriate 
sequences. The helical limits were defined by PredictProtein secondary structure prediction (2) for helices A, B and C and by the crystal structure for helix D. Where relevant, the heptad repeat position, determined by Coils (3) for helix C or by TWISTER (4) for helix D, is listed and the $a$ and $d$ heptad positions are boxed. We have drawn an alternative $\mathrm{N}$-terminal limit for helix C (cylinder in dotted lines) since the heptad repeat and other secondary structure prediction algorithms extend the helix, albeit with a somewhat improbable assignment of H549 in an a position. Double daggers ( $\ddagger)$ indicate the intervening loop, whose sequence is not shown. Asterisks denote insertions that are not included. Colors encode degree of sequence homology as follows: green - identity; yellow - conservative; cyan - marked differences between KCNQ1 and its paralogs. The residue numbering is that of KCNQ1.

\section{References:}

1. $\quad$ Poirot, O., O'Toole, E., and Notredame, C. (2003) Nucleic Acids Res 31, 35033506

2. $\quad$ Rost, B., Yachdav, G., and Liu, J. (2004) Nucleic Acids Res 32, W321-326

3. Lupas, A., Van Dyke, M., and Stock, J. (1991) Science 252, 1162-1164

4. Strelkov, S. V., and Burkhard, P. (2002) J Struct Biol 137, 54-64 


\section{Supplementary Figure 1}

A

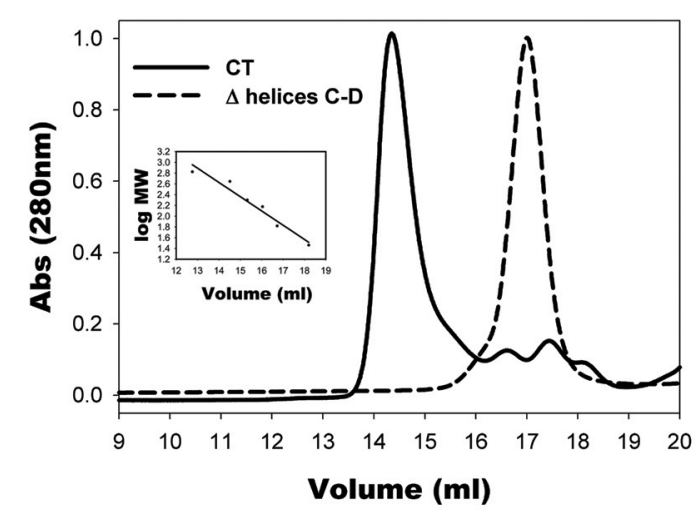

C

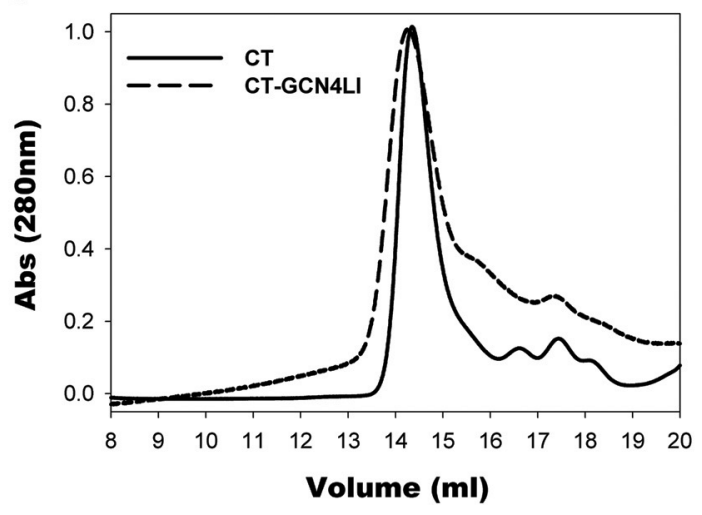

B

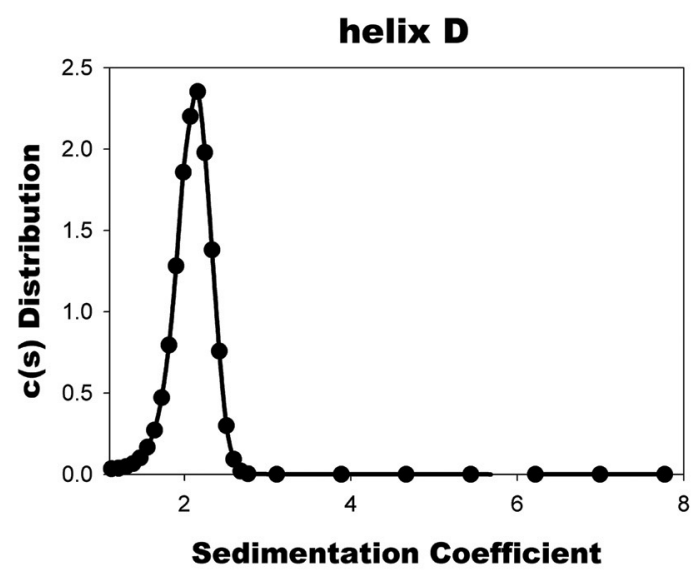

D

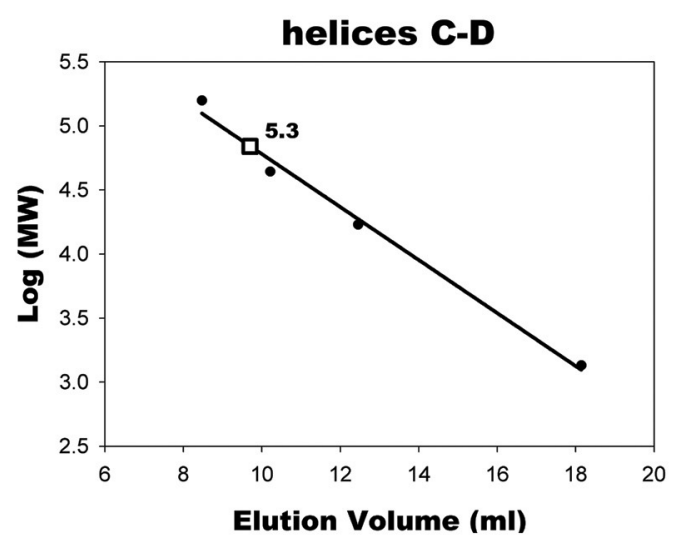




\section{Supplementary Figure 2}

KCNQ1_HUMAN KCNQ1_MOUSE KCNQ1_RAT KCNQ1_DOG KCNQ1_SQUAC KCNQ1_Beetle

KCNQ2 KCNQ3 KCNQ4 KCNQ5

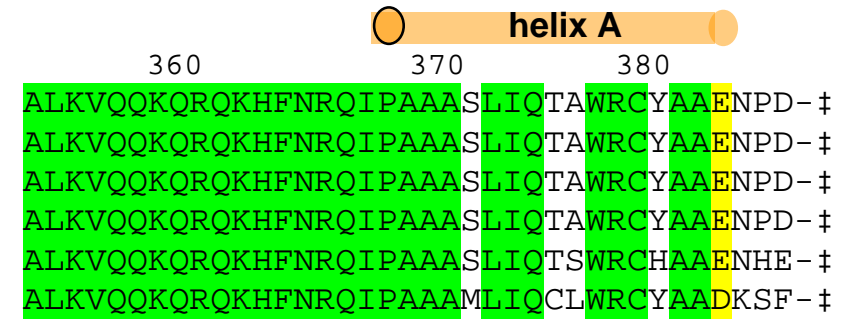

ALKVQEQHRQKHFEKRRNPAAGLIQSAWRFYATNLSR ALKVQEQHRQKHFEKRRKPAAELIQAAWRYYATNPNR ALKVQEQHRQKHFEKRRMPAANLIQAAWRLYSTDMSR ALKVQEQHRQKHFEKRRNPAANLIQCVWRSYAADEKS
KCNQ1_HUMAN KCNQ1_MOUSE KCNQ1_RAT KCNQ1_DOG KCNQ1_SQUAC KCNQ1_Beetle

KCNQ2 KCNQ3 KCNQ4 KCNQ5

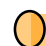
helix B

510

$520 \quad 530$

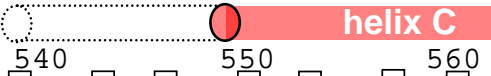

‡-LREHHRATIKVIRRMQYFVAKKKFQQARKPYDVRDVIEQYSQGHLNLMVRIKELQRRLDQ

$\ddagger$-LRDHHRATIKVIRRMQYFVAKKKFQQARKPYDVRDVIEQYSQGHLNLMVRIKELQRRLDQ

$\ddagger$-LRDHHRATIKVIRRMQYFVAKKKFQQARKPYDVRDVIEQYSQGHLNLMVRI KELQRRLLDQ

‡-LREHHRATIKVIRRMQYFVAKKKFQQARKPYDVRDVIEQYSQGHLNLMVRIKELQRRLDQ

‡-LRESHRVTVKVIRRMQYFVAKKKFQQARKPYDVRDVIEQYSQGHLNLMVRIKELQRRLDQ

‡-LTEAHKNAIRAIRKIKYFVARRKFQQARKPYDVRDVIEQYSQGHLNMMVRI KELQRRLDQ

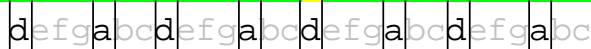

* - LTPGLKVSIRAVCVMRFLVSKRKFKESLRPYDVMDVIEQYSAGHLDMLSRIKSLQSRVDQ

* - MIPTLKAAIRAVRILQFRLYKKKFKETLRPYDVKDVIEQYSAGHLDMLSRIKYLQTRIDM

* - IMPAVKTVIRSIRI LKFLVAKRKFKETLRPYDVKDVIEQYSAGHLDMLGRIKS LQTRVDQ

* - LTPPLKTVIRAIRIMKFHVAKRKFKETLRPYDVKDVIEQYSAGHLDMLCRIKSLLQTRVDQ
KCNQ1_HUMAN

KCNQ1_MOUSE

KCNQ1_RAT

KCNQ1_DOG

KCNQ1_SQUAC

KCNQ1_Beetle

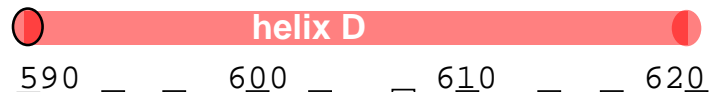

570

580

590

600

610

620

SIGKPSLFISVSEKSKDRGSNTIGARLNRVEDKVTOLDQRLALITDMLHOLLSLHGGSTP SIGKPSLFIPISEKSKDRGSNTIGARLNRVEDKVTQLDQRLVIITDMLHQLLSMQQGGPT SIGKPSLFIPISEKSKDRGSNTIGARLNRVEDKVTQLDQRLVIITDMLHQLLSLQQGGPT SIGKPSLFISVSEKSKDRGSNTIGARLNRVEDKVTQLDQRLVLITDMLHQLLSLYHGGPP SLGKPTMFLSVSEKSQDRGKNTIGARLNRVEEKFVHMDQKLNTIT DMLHHLVAHQQGHPH TLGKPGSYLAGIDRVGNVKPMTVGAR LYRVEQQLGTMDKKLDALTHILNSLAQKNQAAPL

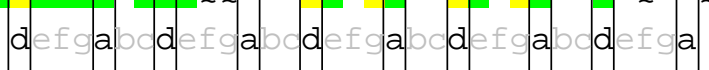

KCNQ2 * -AITDK-DR-TKGPAEAELPEDPSMMGRLGKVEKQVLSMEKKLDFLVNIYMQRMGI- - PPTETEA KCNQ3 * -PSTPKHKKSQKGSASTSEIEDQSMMGKFVKVVERQVQDMGKKLDFLVDMHMQHMER - - LQVQVTE KCNQ4 * -GDRKAREKGDKGPSDAEVVDEISMMGRVVKVEKQVQSIEHKLDLLLGFYSRCLRSGTSASL G - KCNQ5 * - ITSDKKSRE-KITAEHETTDDLSMLGRVVKVEKQVQSIESKLDCLLDIYQQVLRKGSASALAL 


\section{The KCNQ1 (Kv7.1) COOH Terminus, a Multitiered Scaffold for Subunit Assembly and Protein Interaction}

Reuven Wiener, Yoni Haitin, Liora Shamgar, M. Carmen Fernández-Alonso, Ariadna Martos, Orna Chomsky-Hecht, Germán Rivas, Bernard Attali and Joel A. Hirsch

J. Biol. Chem. 2008, 283:5815-5830.

doi: 10.1074/jbc.M707541200 originally published online December 29, 2007

Access the most updated version of this article at doi: 10.1074/jbc.M707541200

Alerts:

- When this article is cited

- When a correction for this article is posted

Click here to choose from all of JBC's e-mail alerts

Supplemental material:

http://www.jbc.org/content/suppl/2008/01/03/M707541200.DC1

This article cites 44 references, 17 of which can be accessed free at http://www.jbc.org/content/283/9/5815.full.html\#ref-list-1 